\title{
Manual Annotation of the Mouse Genome: HAVANA and EUCOMM
}

\author{
Mark Thomas
}




\section{Overview}

- HAVANA

- Otterlace and Zmap

- Annotation and Vector Design

- EUCOMM

- Objectives

- Conditional Targeting

- VEGA

- Results (current status)

- Annotation

- High Throughput Gene Targeting (HTGT) resource 


\section{HAVANA}




\section{HAVANA - manual annotation}

- Otterlace used to manually annotate finished genomic sequence (primarily human, mouse and zebrafish) [Posters $\mathrm{A} 3, \mathrm{C} 12$ and $\mathrm{C} 22$ ]

- Annotation based on mRNA, EST and protein homology evidence only

- Annotation includes;

- All transcripts including splice variants

- Gene clusters

- Pseudogenes

- PolyA features 


\section{HAVANA - annotation pipeline}

Finished sequence

Otter DB MySQL
Automated analysis

Manual Annotation

Ensembl

\section{EMBL}

- BLAST (mRNA, EST, protein)

- Gene Prediction (Genscan, Augustus)

- RepeatMasker and TRF

- CpG island prediction

- Pfam

- RefSeq and Ensembl structures

- PhastCons / Ditag / CAGEtag

- LACE - transcript editing interface

- ZMAP - graphical interface

\section{VEGA

$$
\text { VEGA }
$$

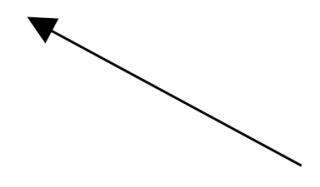

Otter and VEGA databases based on Ensembl schema

Linux and Mac distributions 


\section{HAVANA - Otterlace and Zmap}

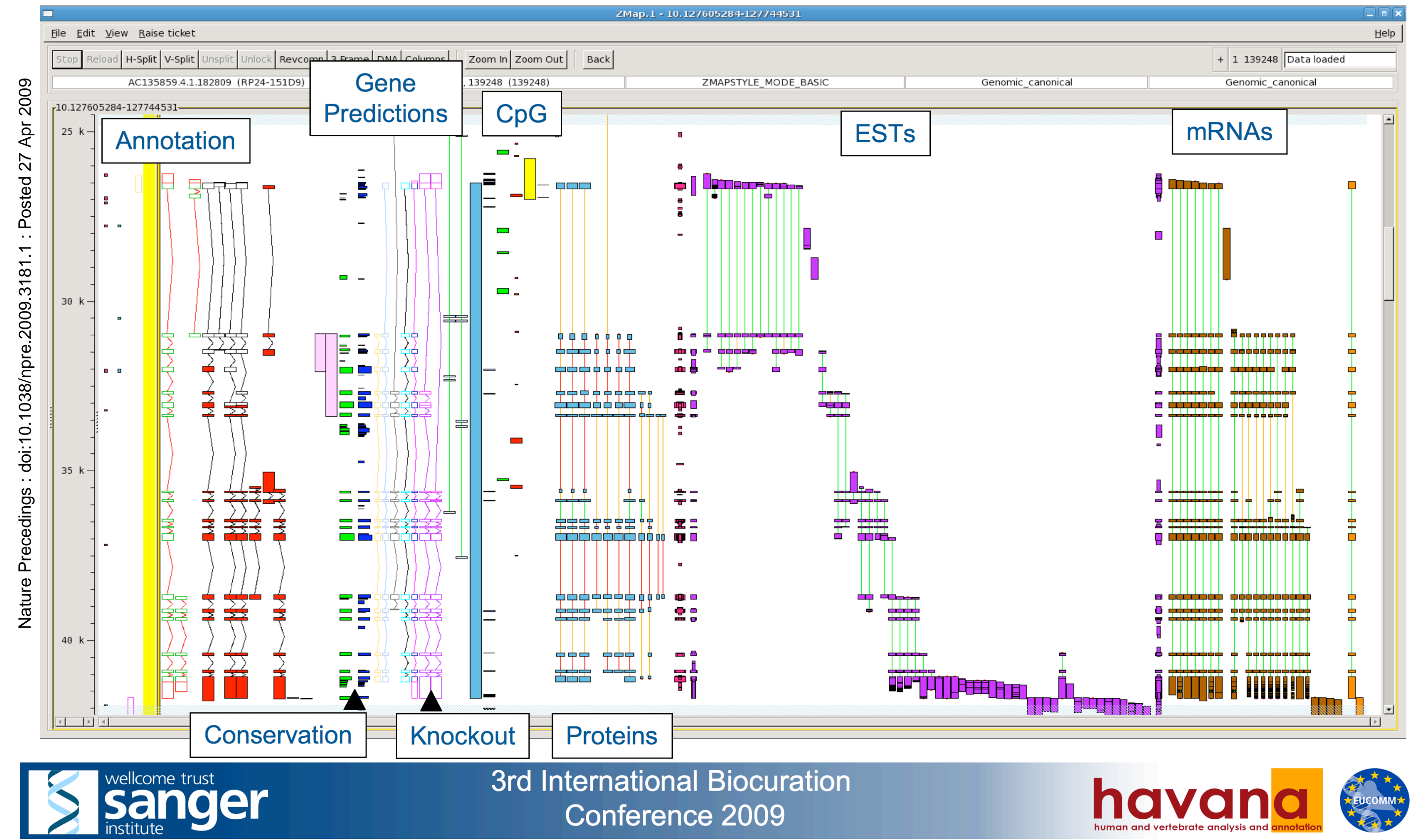




\section{HAVANA - Otterlace and Zmap}

\begin{tabular}{l} 
\\
\hline
\end{tabular}

$\square$

lace chr10-03, clone 949

$-\square x$

ESTT59605

ESTT59607

MUST 105247

MUST 92033

$\operatorname{CCDS} 24261.1$

ESTT59424

MUST99139

ESTT5 9604

PFO1199. 1

KO: RP24-151D9 - 3-002

KO: RP24-15109.3-001

RP24-151D9.3-001

PF0 4960. 1

augustus. 4

P.P24-151D9.3-010 ESTT 59440

P.P24-151D9.3-003 R.P24-15109.3-009

RP24-15109 3-007

augustus. 8

P.P24-15109-3-008

RP24-1509.3-008

RP24-15109.3-002

ESTT59429

PiP24-15109.3-011

genscan.

PP24-151D9.3-006

RP24-151D9.3-005 PF05029.1

MUST $44776 \quad$ RP24-151D9.1-008

ESTT59427 R.P24-151D9.1-015

RP24-151D9.3-004 RP24-151D9.1-007

R.P24-151D9 . 1-014

R.P24-151D9 - 1-013

RP24-151D9.1-012

genscan . 6

augustus. 7

MUST 61995

ESTT 59500

ESTT59498

ESTT 59498

ESTT 59491

PFO2864. 1

PFO2865. 1

genscan. 2

CCDS2 4269.1
augustus.

augustus. 2
MUST105238

MUST 85708

ESTT59486

ESTT59488

ESTT59489

ESTT59476

genscan 4

augustus. 1

CCDS24268.

MUST 50901

MUST50901

CCDs2426?

MUST 105239

MUST60782

15109 . 1-017

RP24-151D9 - 1-016 ESTT 59473

1D9 - 1-011

PFO 4821.1

augustus. 6

PP24-151D9 1-006

MUST 105245

R.P24-151D9 - 1-002

RP24-151D9 - 1-005

RP24-151D9.1-010

MUST55539

MUST105246

RP24-151D9 - 1-009

R.P24-151D9 _ 1-003

PP24-151D9 -1-004

RP24-151D9 - 1-001

ESTT59470

PFO0230.1

CCDS2 4265.1

augustus. 3

ESTT59445

Mo: 2645

RP24-151D9 2-001 genscan 5
OTTMUST00000059536

KO: P.P24-151D9 - 1-001

151D9 2-001

MUST 83014

genscan. 3

$\operatorname{CCDS} 24270.1$

augustus. 5

MUST 26449

$\cos 24271.1$

ESTT 59510

ESTT 59508

ESTT59507

MUST 105237

MUST 5825

Find Clear

|年 $\frac{1}{3} \frac{1}{5}$

Conservation
Knockout

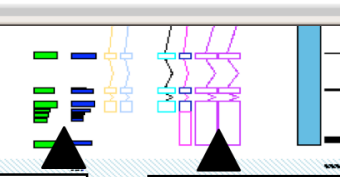

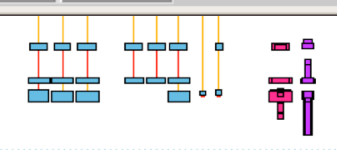

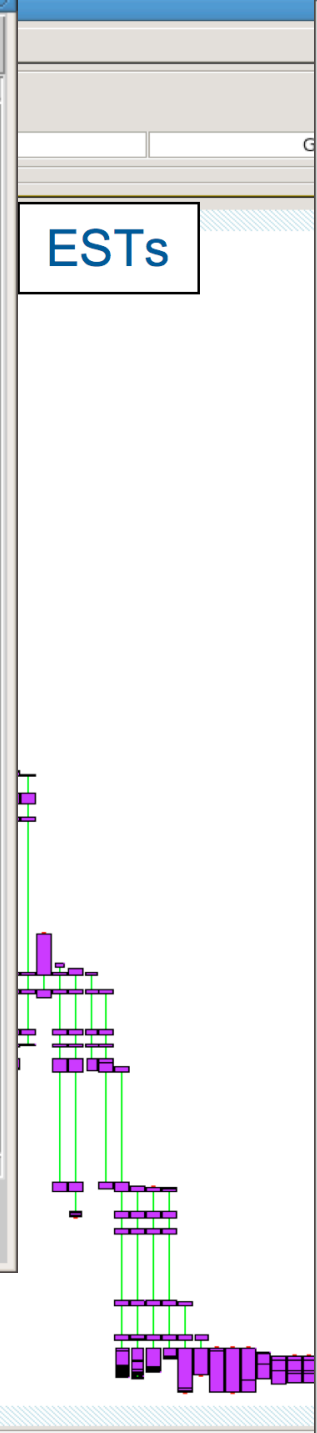

딘원

RP24-15 ID9.3-00 I

File Exon Iools

26499

26230 ॠ 26680

30955 대 31054

31410 내 31531

31946 32075

32659 32738

32979 다 33142

33332 다 3

35596 35628

35848 35906

36434 36500

36634 대 36684

36861 ㄴ 37037

38645 ㄴ 38776

39071 눈 39163

39334 내 39395

40364 凸 40440

40879 다 40942

41061 난 41712

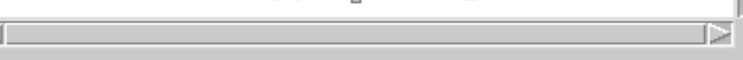

Transcript

Name: RP24-151D9, 3-001

Type: Known_CDS

Start: Found $\quad-$ End: Found

Remarks:

Annotation

Locus

Symbol: 0152

$\pm \square$ Known

Full name: glutaminase 2 (liver, mitochondrial)

Alias(es):

Remarks

Annotation 


\section{HAVANA - Otterlace and Zmap}

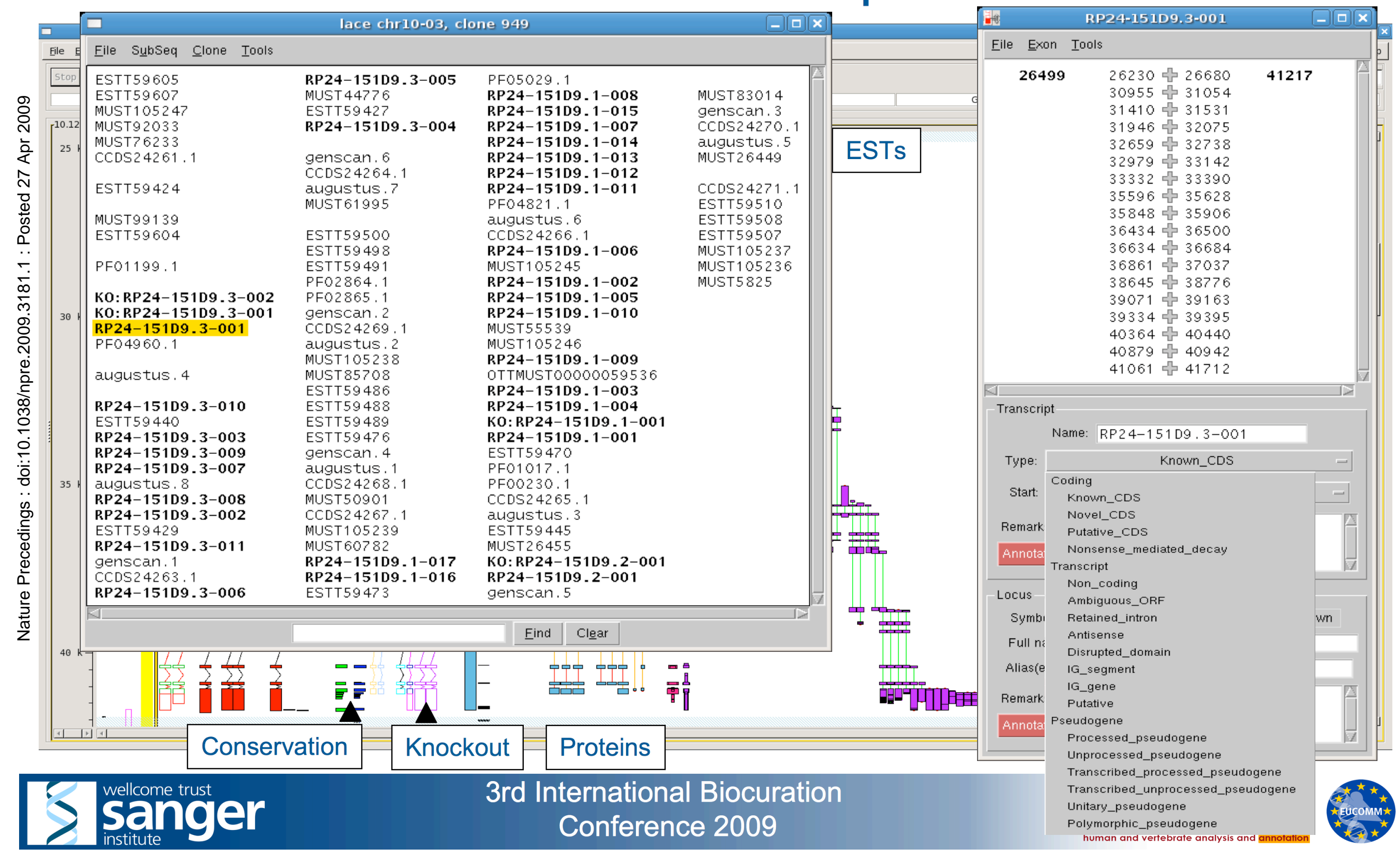




\section{HAVANA - Otterlace and Zmap}

\begin{tabular}{l} 
\\
\hline
\end{tabular}

$\square$

lace chr10-03, clone 949

$-\square x$

ESTT59605

ESTT59607

MUST 105247

MUST 92033

$\operatorname{CCDS} 24261.1$

ESTT59424

MUST99139

ESTT5 9604

PFO1199. 1

KO: RP24-151D9 - 3-002

KO: RP24-15109.3-001

RP24-151D9.3-001

PF0 4960. 1

augustus. 4

P.P24-151D9.3-010 ESTT 59440

P.P24-151D9.3-003 R.P24-15109.3-009

RP24-15109 3-007

augustus. 8

P.P24-15109-3-008

RP24-1509.3-008

RP24-15109.3-002

ESTT59429

PiP24-15109.3-011

genscan.

PP24-151D9.3-006

RP24-151D9.3-005 PF05029.1

MUST $44776 \quad$ RP24-151D9.1-008

ESTT59427 R.P24-151D9.1-015

RP24-151D9.3-004 RP24-151D9.1-007

R.P24-151D9 . 1-014

R.P24-151D9 - 1-013

RP24-151D9.1-012

genscan . 6

augustus. 7

MUST 61995

ESTT 59500

ESTT59498

ESTT 59498

ESTT 59491

PFO2864. 1

PFO2865. 1

genscan. 2

CCDS2 4269.1
augustus.

augustus. 2
MUST105238

MUST 85708

ESTT59486

ESTT59488

ESTT59489

ESTT59476

genscan 4

augustus. 1

CCDS24268.

MUST 50901

MUST50901

CCDs2426?

MUST 105239

MUST60782

15109 . 1-017

RP24-151D9 - 1-016 ESTT 59473

1D9 - 1-011

PFO 4821.1

augustus. 6

PP24-151D9 1-006

MUST 105245

R.P24-151D9 - 1-002

RP24-151D9 - 1-005

RP24-151D9.1-010

MUST55539

MUST105246

RP24-151D9 - 1-009

R.P24-151D9 _ 1-003

PP24-151D9 -1-004

RP24-151D9 - 1-001

ESTT59470

PFO0230.1

CCDS2 4265.1

augustus. 3

ESTT59445

Mo: 2645

RP24-151D9 2-001 genscan 5
OTTMUST00000059536

KO: P.P24-151D9 - 1-001

151D9 2-001

MUST 83014

genscan. 3

$\operatorname{CCDS} 24270.1$

augustus. 5

MUST 26449

$\cos 24271.1$

ESTT 59510

ESTT 59508

ESTT59507

MUST 105237

MUST 5825

Find Clear

|年 $\frac{1}{3} \frac{1}{5}$

Conservation
Knockout

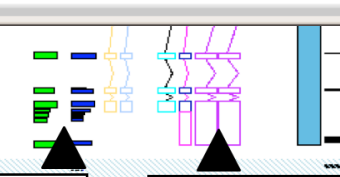

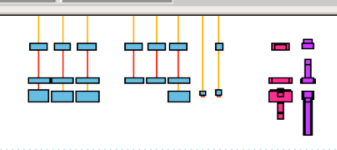

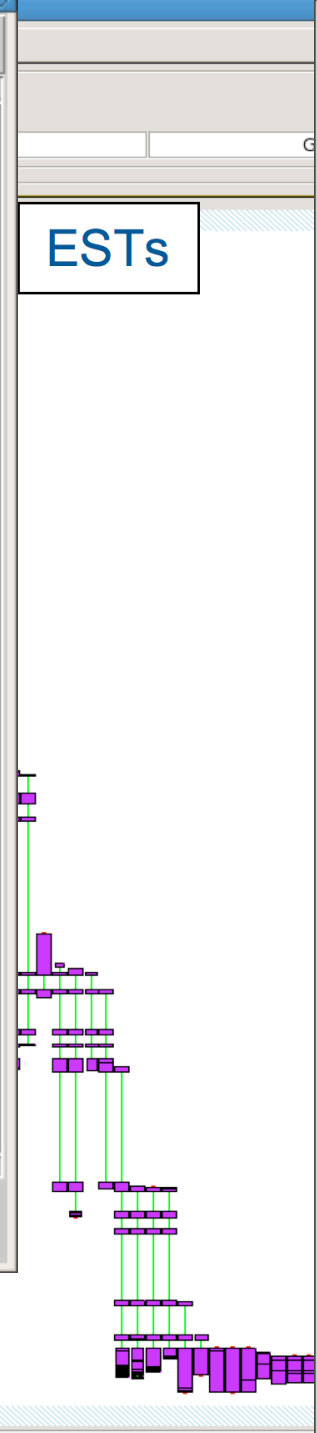

딘원

RP24-15 ID9.3-00 I

File Exon Iools

26499

26230 ॠ 26680

30955 대 31054

31410 내 31531

31946 32075

32659 32738

32979 다 33142

33332 다 3

35596 35628

35848 35906

36434 36500

36634 대 36684

36861 ㄴ 37037

38645 ㄴ 38776

39071 눈 39163

39334 내 39395

40364 凸 40440

40879 다 40942

41061 난 41712

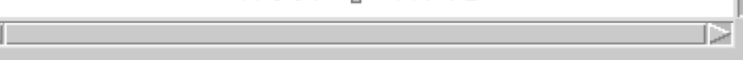

Transcript

Name: RP24-151D9, 3-001

Type: Known_CDS

Start: Found $\quad-$ End: Found

Remarks:

Annotation

Locus

Symbol: 0152

$\pm \square$ Known

Full name: glutaminase 2 (liver, mitochondrial)

Alias(es):

Remarks

Annotation 


\section{HAVANA - Otterlace and Zmap}

\begin{tabular}{l} 
\\
\hline
\end{tabular}

$\square$

lace chr10-03, clone 949

$-\square x$

ESTT59605

ESTT59607

MUST 105247

MUST 92033

$\operatorname{CCDS} 24261.1$

ESTT59424

MUST99139

ESTT5 9604

PFO1199. 1

KO: RP24-151D9 - 3-002

KO: RP24-15109.3-001

RP24-151D9.3-001

PF0 4960. 1

augustus. 4

P.P24-151D9.3-010 ESTT 59440

P.P24-151D9.3-003 R.P24-15109.3-009

RP24-15109 3-007

augustus. 8

P.P24-15109-3-008

RP24-1509.3-008

RP24-15109.3-002

ESTT59429

PiP24-15109.3-011

genscan.

PP24-151D9.3-006

RP24-151D9.3-005 PF05029.1

MUST $44776 \quad$ RP24-151D9.1-008

ESTT59427 R.P24-151D9.1-015

RP24-151D9.3-004 RP24-151D9.1-007

R.P24-151D9 . 1-014

R.P24-151D9 - 1-013

RP24-151D9.1-012

genscan . 6

augustus. 7

MUST 61995

ESTT 59500

ESTT59498

ESTT 59498

ESTT 59491

PFO2864. 1

PFO2865. 1

genscan. 2

CCDS2 4269.1
augustus.

augustus. 2
MUST105238

MUST 85708

ESTT59486

ESTT59488

ESTT59489

ESTT59476

genscan 4

augustus. 1

CCDS24268.

MUST 50901

MUST50901

CCDs2426?

MUST 105239

MUST60782

15109 . 1-017

RP24-151D9 - 1-016 ESTT 59473

1D9 - 1-011

PFO 4821.1

augustus. 6

PP24-151D9 1-006

MUST 105245

R.P24-151D9 - 1-002

RP24-151D9 - 1-005

RP24-151D9.1-010

MUST55539

MUST105246

RP24-151D9 - 1-009

R.P24-151D9 _ 1-003

PP24-151D9 -1-004

RP24-151D9 - 1-001

ESTT59470

PFO0230.1

CCDS2 4265.1

augustus. 3

ESTT59445

Mo: 2645

RP24-151D9 2-001 genscan 5
OTTMUST00000059536

KO: P.P24-151D9 - 1-001

151D9 2-001

MUST 83014

genscan. 3

$\operatorname{CCDS} 24270.1$

augustus. 5

MUST 26449

$\cos 24271.1$

ESTT 59510

ESTT 59508

ESTT59507

MUST 105237

MUST 5825

Find Clear

|年 $\frac{1}{3} \frac{1}{5}$

Conservation
Knockout

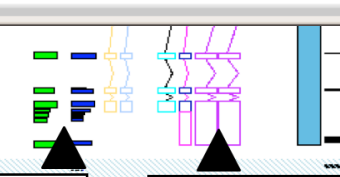

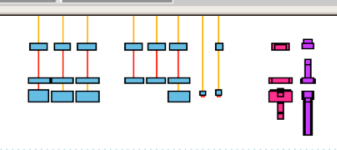

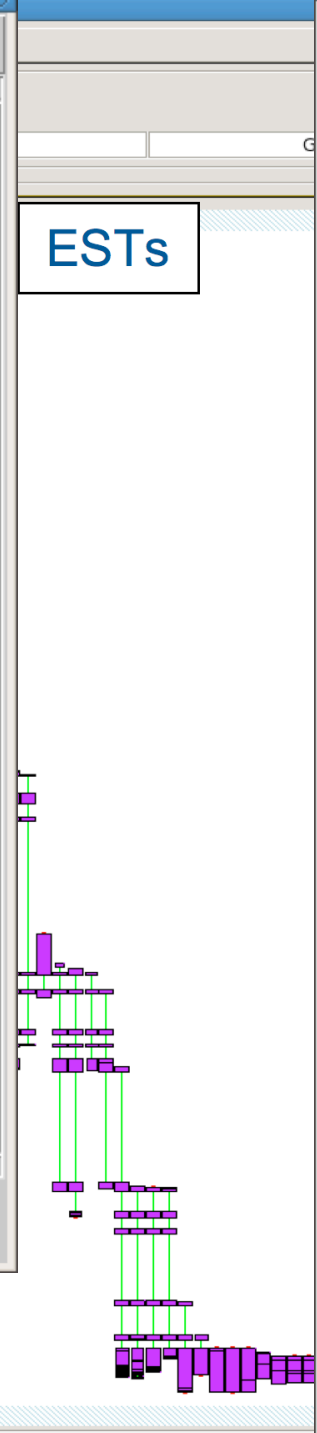

딘원

RP24-15 ID9.3-00 I

File Exon Iools

26499

26230 ॠ 26680

30955 대 31054

31410 내 31531

31946 32075

32659 32738

32979 다 33142

33332 다 3

35596 35628

35848 35906

36434 36500

36634 대 36684

36861 ㄴ 37037

38645 ㄴ 38776

39071 눈 39163

39334 내 39395

40364 凸 40440

40879 다 40942

41061 난 41712

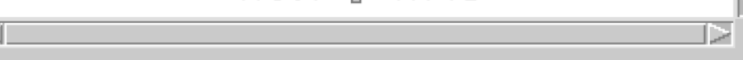

Transcript

Name: RP24-151D9, 3-001

Type: Known_CDS

Start: Found $\quad-$ End: Found

Remarks:

Annotation

Locus

Symbol: 0152

$\pm \square$ Known

Full name: glutaminase 2 (liver, mitochondrial)

Alias(es):

Remarks

Annotation 


\section{HAVANA - Otterlace and Zmap}

\begin{tabular}{l} 
\\
\hline
\end{tabular}

$\square$

lace chr10-03, clone 949

ESTT59605

ESTT 59607
MUUST 105247

MUUST105247
MUST 92033

MUST 92033

$\operatorname{CCDS} 24261.1$

ESTT59424

MUST99139

ESTT59604

PFO1199. 1

KO: RP24-151D9 -3-002

KO: RP24-151D9.3-00

RP24-151D9 . 3-001

PFO 4960. 1

augustus. 4

P.P24-151D9 . 3-010 ESTT 59440

R.P24-151D9.3-003 R.P24-151D9.3-009

RP24-15109 3-007

augustus. 8

PP24-15109 3-008

RP24-151D - 3-008

RP24-15109.3-002

ESTT59429

P.P24-15109.3-011

genscan. 1

PP24-151D9.3-006

RP24-151D9.3-005 PFO5029.1

MUST $44776 \quad$ RP24-151D9.1-008

ESTT59427 R.P24-151D9.1-015

RP24-151D9.3-004 RP24-151D9.1-007

RP24-151D9.1-014

R.P24-151D9 - 1-013

RP24-151D9 -1-012

genscan . 6

augustus. 7

MUST61995

ESTT59500

ESTT59498

ESTT 59498

ESTT 59491

PFO2864. 1

PFO2865. 1

genscan. 2

$\operatorname{cCDS} 24269$.

augustus. 2
MusT105238

MUST 85708

ESTT59486

ESTT59488

ESTT59489

ESTT59476

genscan 4

augustus. 1

CCDS24268.

MUST 50901

MUST50901

CCDS2 4267 .

MUST105239

MUST60782

RP24-15109 1-017

RP24-151D9 - 1-016 ESTT59473

RP24-151D9 - 1-011

PFO 4821.1

augustus. 6

P.P24-15109 1-006

MUST105245

RP24-151D9 . 1-002

RP24-151D9 - 1-005

RP24-151D9.1-010

MUST55539

MUST 105246

RP24-151D9 - 1-009

R.P24-151D9 _ 1-003

PP24-151D9 -1-004

RP24-151D9 - 1-001

ESTT59470

PFO $0230 \cdot 1$

CCDS24265.1

CCDS24265.

a 9 TT 5445

ESTT59445

MO:

RP24-151D9.2-001 genscan. 5
OTTMUSTO0000059536

KO: R.P24-151D9 - 1-001

151D9 2-001

MUST 83014

genscan. 3

$\cos 24270.1$

augustus. 5

MUST 26449

$\cos 24271.1$

ESTT 59510

ESTT 59508

ESTT59507

MUST105237

MUST 5825

Find Clear

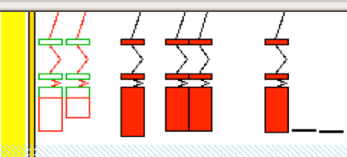

Conservation

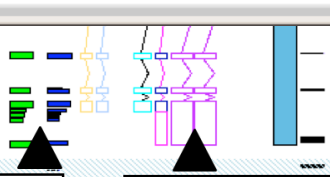

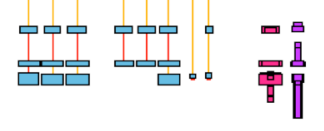

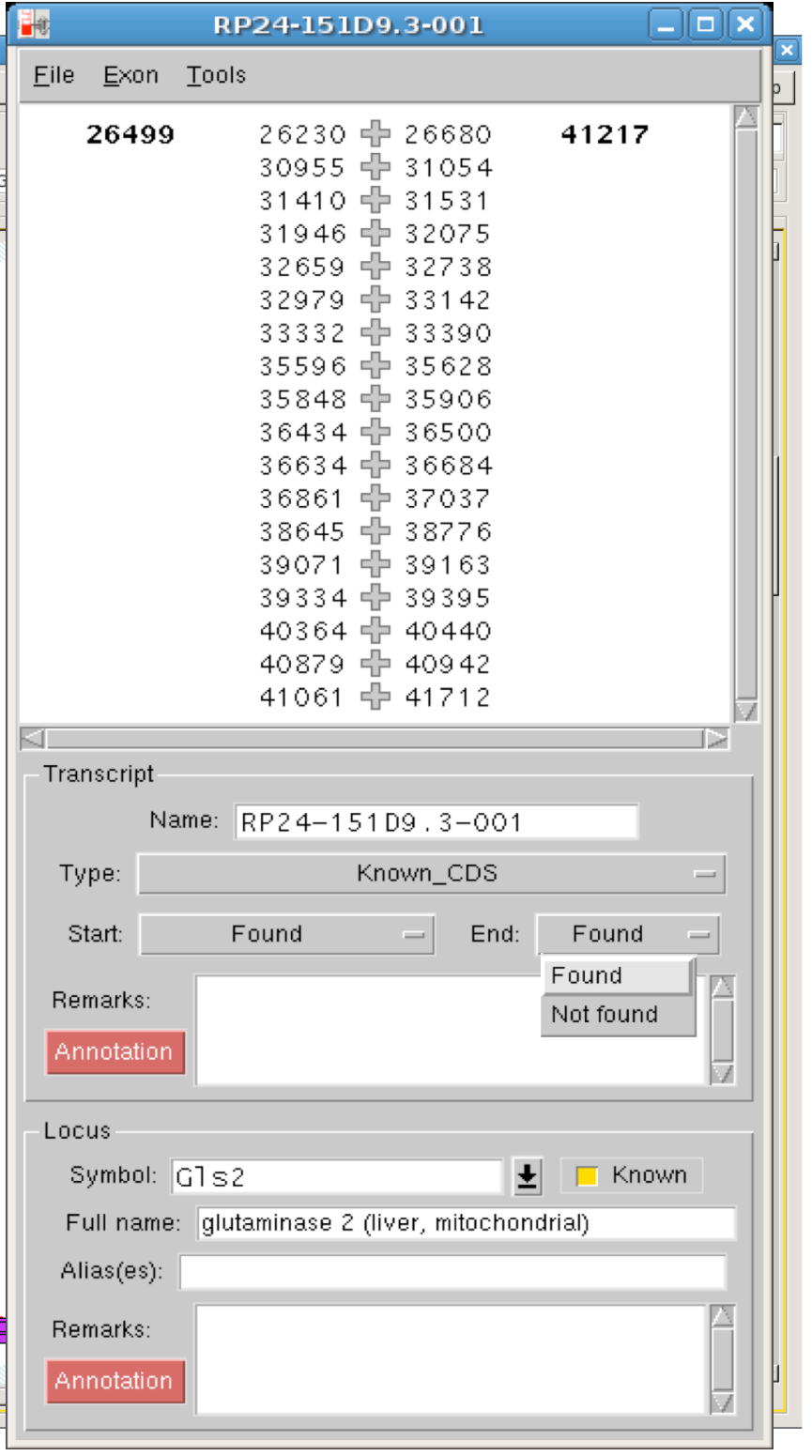

havana 


\section{HAVANA - Otterlace and Zmap}

\begin{tabular}{l} 
\\
\hline
\end{tabular}

$\square$

lace chr10-03, clone 949

$-\square x$

ESTT59605

ESTT59607

MUST 105247

MUST 92033

$\operatorname{CCDS} 24261.1$

ESTT59424

MUST99139

ESTT5 9604

PFO1199. 1

KO: RP24-151D9 - 3-002

KO: RP24-15109.3-001

RP24-151D9.3-001

PF0 4960. 1

augustus. 4

P.P24-151D9.3-010 ESTT 59440

P.P24-151D9.3-003 R.P24-15109.3-009

RP24-15109 3-007

augustus. 8

P.P24-15109-3-008

RP24-1509.3-008

RP24-15109.3-002

ESTT59429

PiP24-15109.3-011

genscan.

PP24-151D9.3-006

RP24-151D9.3-005 PF05029.1

MUST $44776 \quad$ RP24-151D9.1-008

ESTT59427 R.P24-151D9.1-015

RP24-151D9.3-004 RP24-151D9.1-007

R.P24-151D9 . 1-014

R.P24-151D9 - 1-013

RP24-151D9.1-012

genscan . 6

augustus. 7

MUST 61995

ESTT 59500

ESTT59498

ESTT 59498

ESTT 59491

PFO2864. 1

PFO2865. 1

genscan. 2

CCDS2 4269.1
augustus.

augustus. 2
MUST105238

MUST 85708

ESTT59486

ESTT59488

ESTT59489

ESTT59476

genscan 4

augustus. 1

CCDS24268.

MUST 50901

MUST50901

CCDs2426?

MUST 105239

MUST60782

15109 . 1-017

RP24-151D9 - 1-016 ESTT 59473

1D9 - 1-011

PFO 4821.1

augustus. 6

PP24-151D9 1-006

MUST 105245

R.P24-151D9 - 1-002

RP24-151D9 - 1-005

RP24-151D9.1-010

MUST55539

MUST105246

RP24-151D9 - 1-009

R.P24-151D9 _ 1-003

PP24-151D9 -1-004

RP24-151D9 - 1-001

ESTT59470

PFO0230.1

CCDS2 4265.1

augustus. 3

ESTT59445

Mo: 2645

RP24-151D9 2-001 genscan 5
OTTMUST00000059536

KO: P.P24-151D9 - 1-001

151D9 2-001

MUST 83014

genscan. 3

$\operatorname{CCDS} 24270.1$

augustus. 5

MUST 26449

$\cos 24271.1$

ESTT 59510

ESTT 59508

ESTT59507

MUST 105237

MUST 5825

Find Clear

|年 $\frac{1}{3} \frac{1}{5}$

Conservation
Knockout

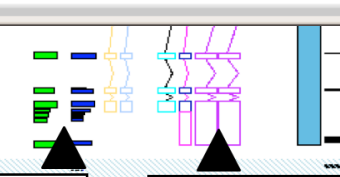

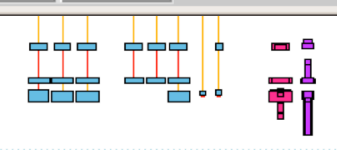

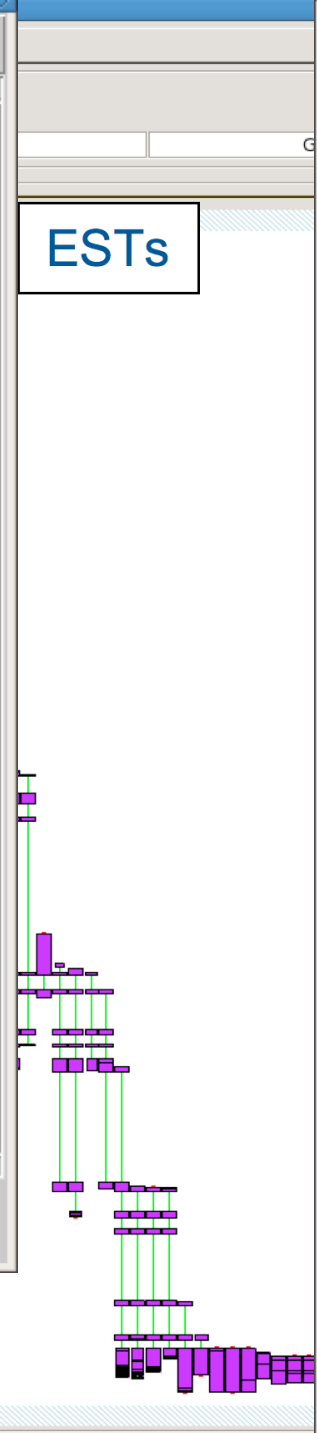

딘원

RP24-15 ID9.3-00 I

File Exon Iools

26499

26230 ॠ 26680

30955 대 31054

31410 내 31531

31946 32075

32659 32738

32979 다 33142

33332 다 3

35596 35628

35848 35906

36434 36500

36634 대 36684

36861 ㄴ 37037

38645 ㄴ 38776

39071 눈 39163

39334 내 39395

40364 凸 40440

40879 다 40942

41061 난 41712

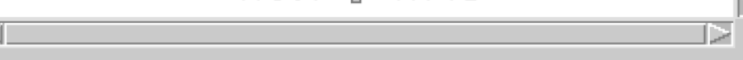

Transcript

Name: RP24-151D9, 3-001

Type: Known_CDS

Start: Found $\quad-$ End: Found

Remarks:

Annotation

Locus

Symbol: 0152

$\pm \square$ Known

Full name: glutaminase 2 (liver, mitochondrial)

Alias(es):

Remarks

Annotation 


\section{HAVANA - Otterlace and Zmap}

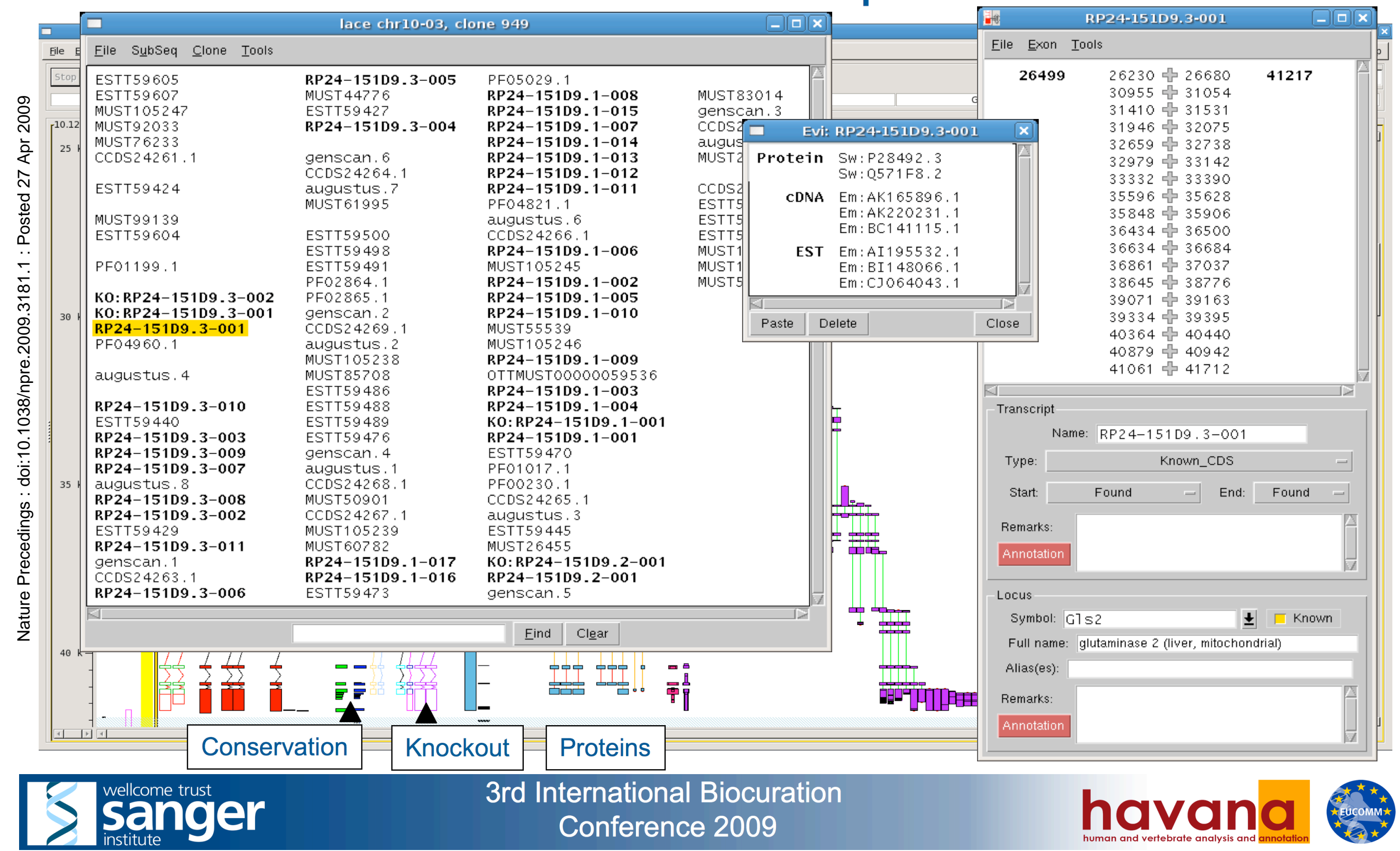




\section{HAVANA - Otterlace and Zmap}

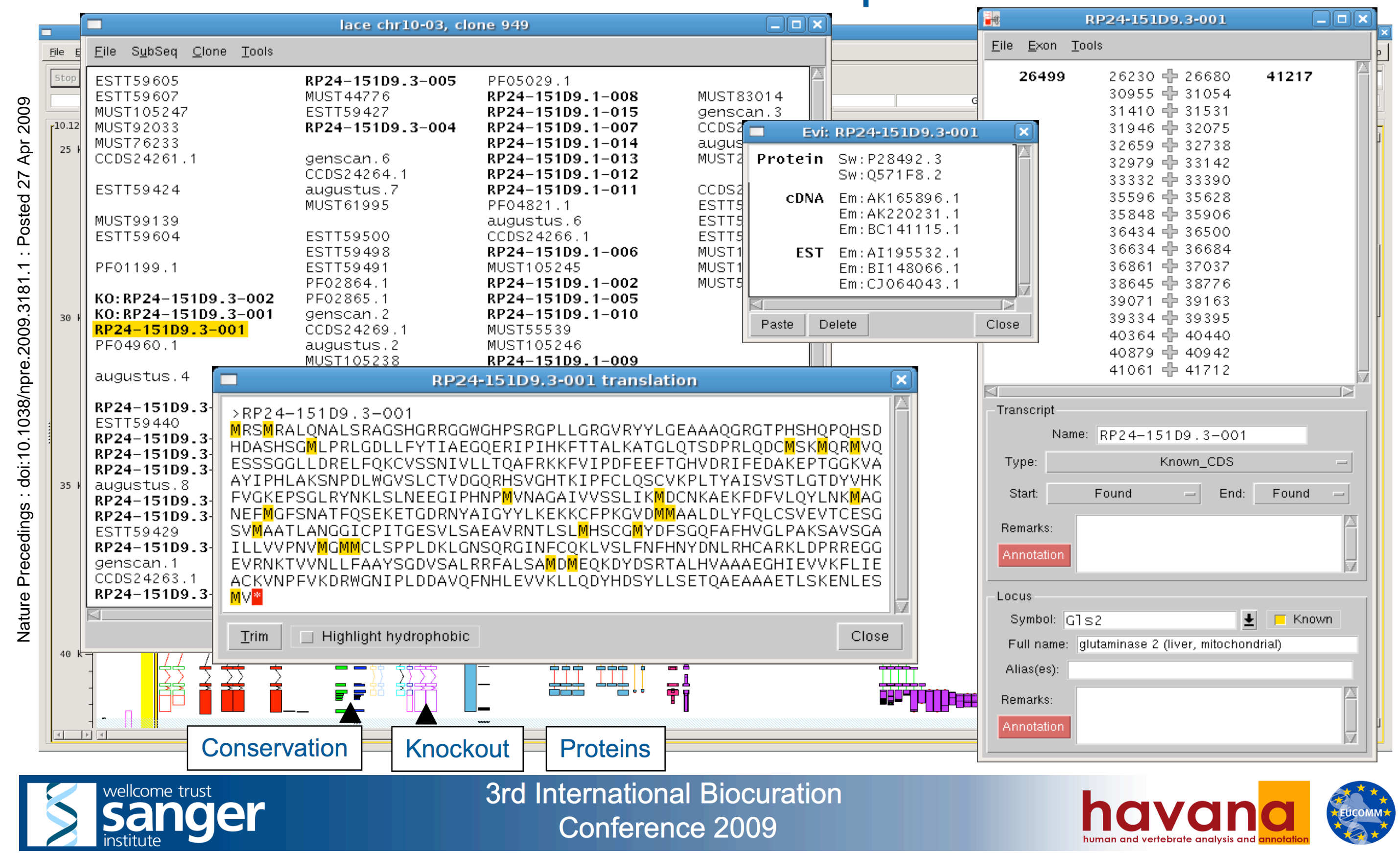




\section{HAVANA - Otterlace and Zmap}

\section{Additional Tools}

- Blixem - multiple alignment

- Dotter - pairwise alignment

- Cross-Species
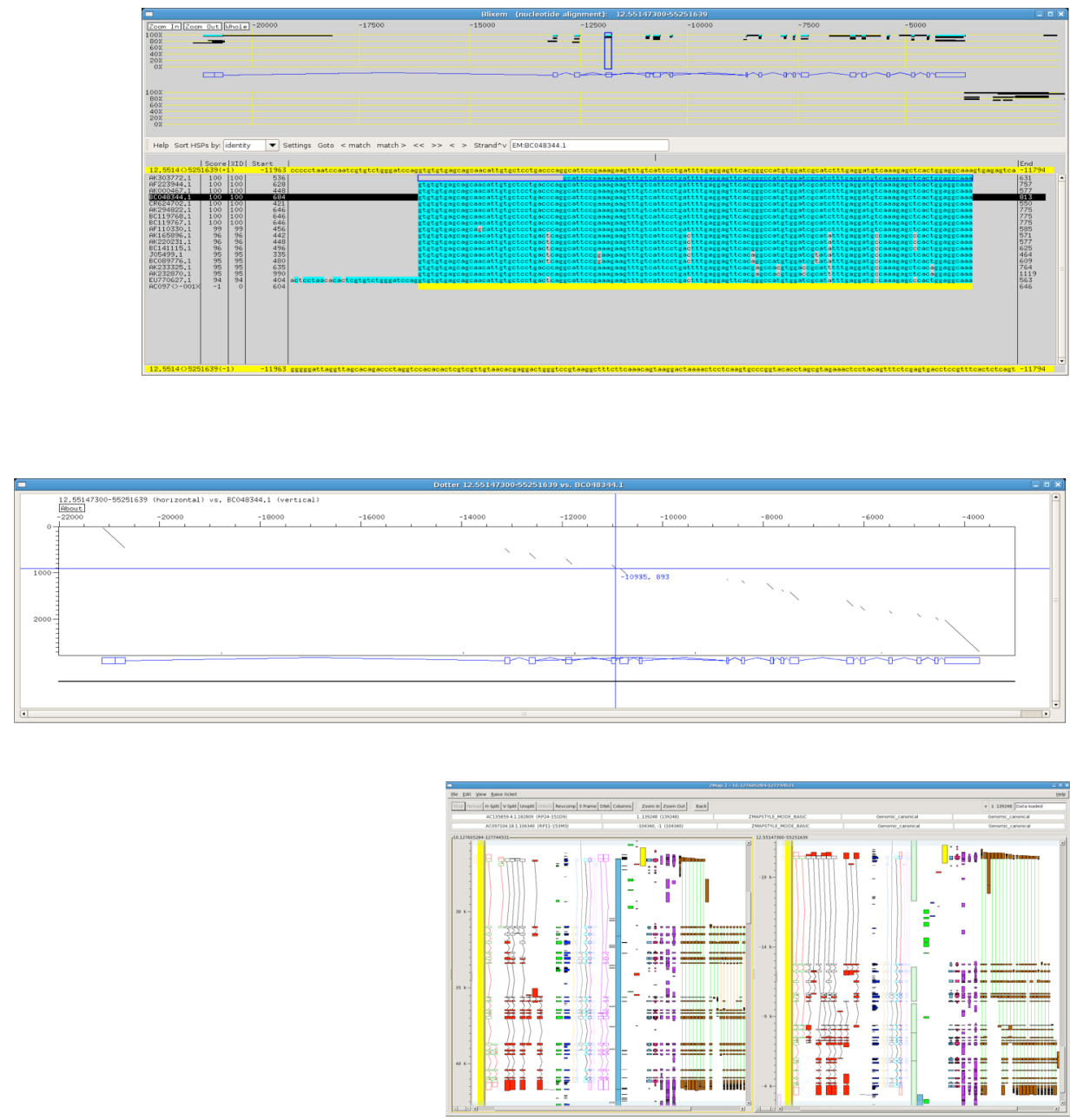

\section{havana}




\section{HAVANA - Otterlace and Zmap}

\section{Additional Tools}

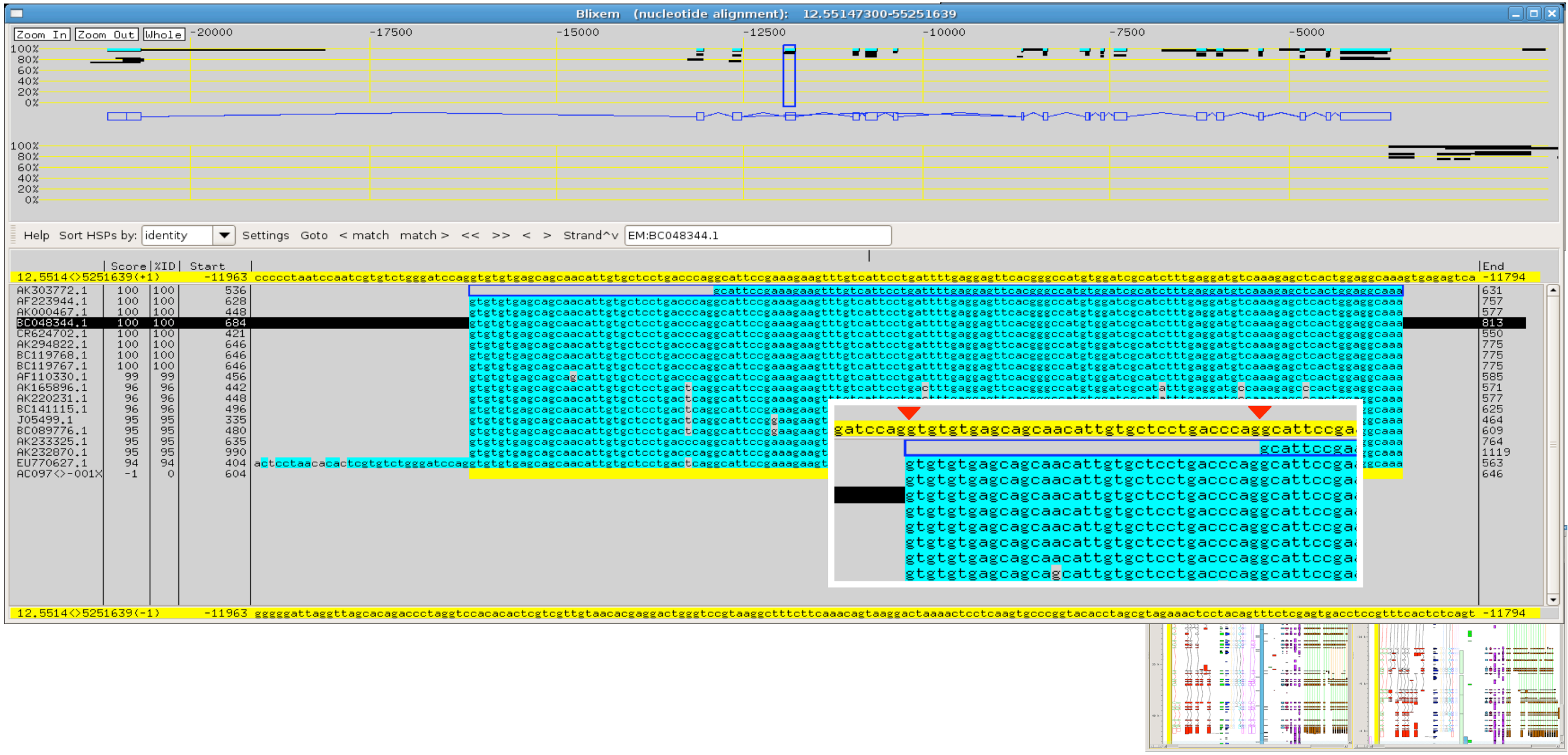




\section{HAVANA - Otterlace and Zmap}

\section{Additional Tools}

- Blixem - multiple alignment

- Dotter - pairwise alignment

- Cross-Species
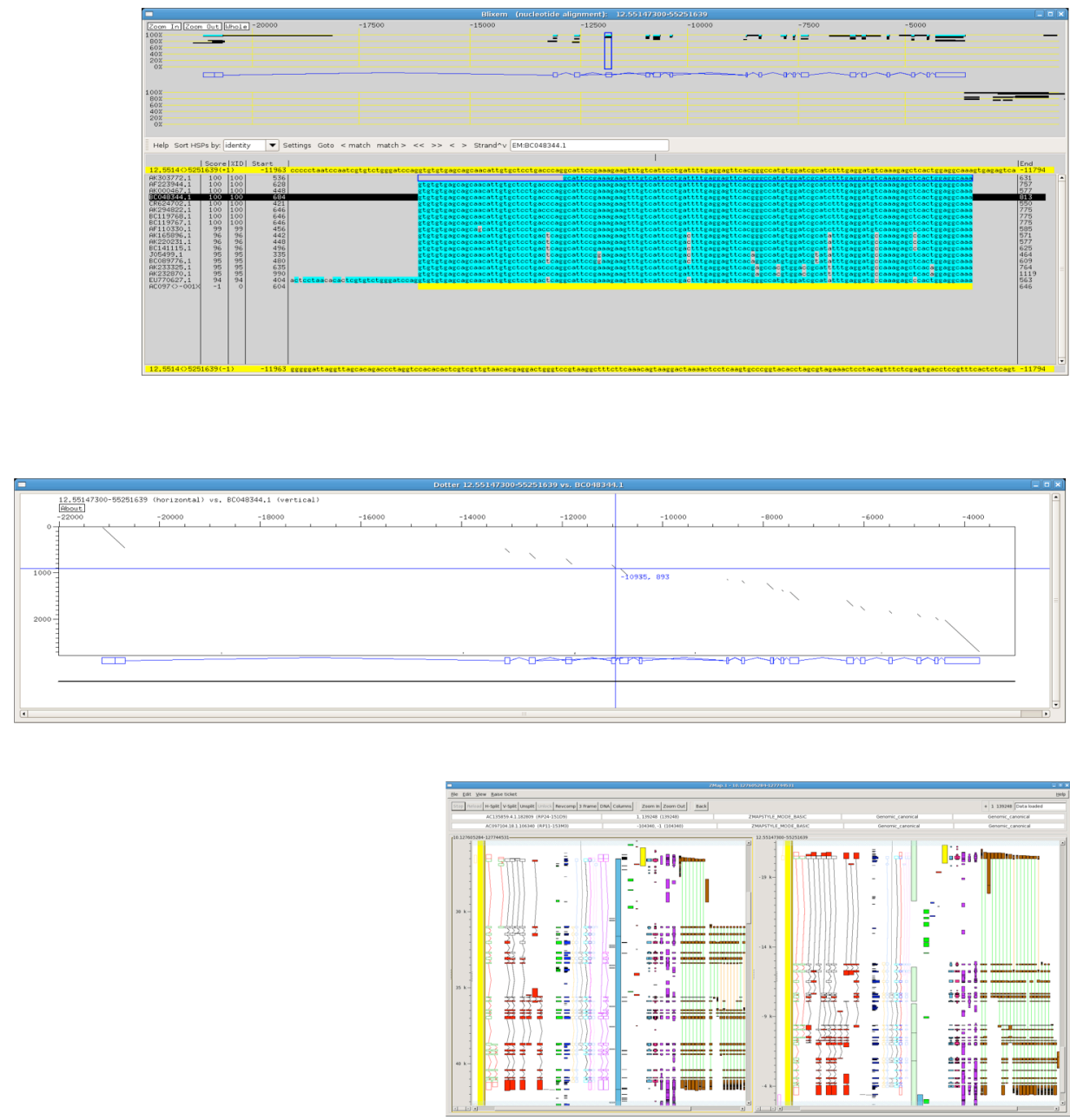

\section{havana}




\section{HAVANA - Otterlace and Zmap}

\section{Additional Tools}

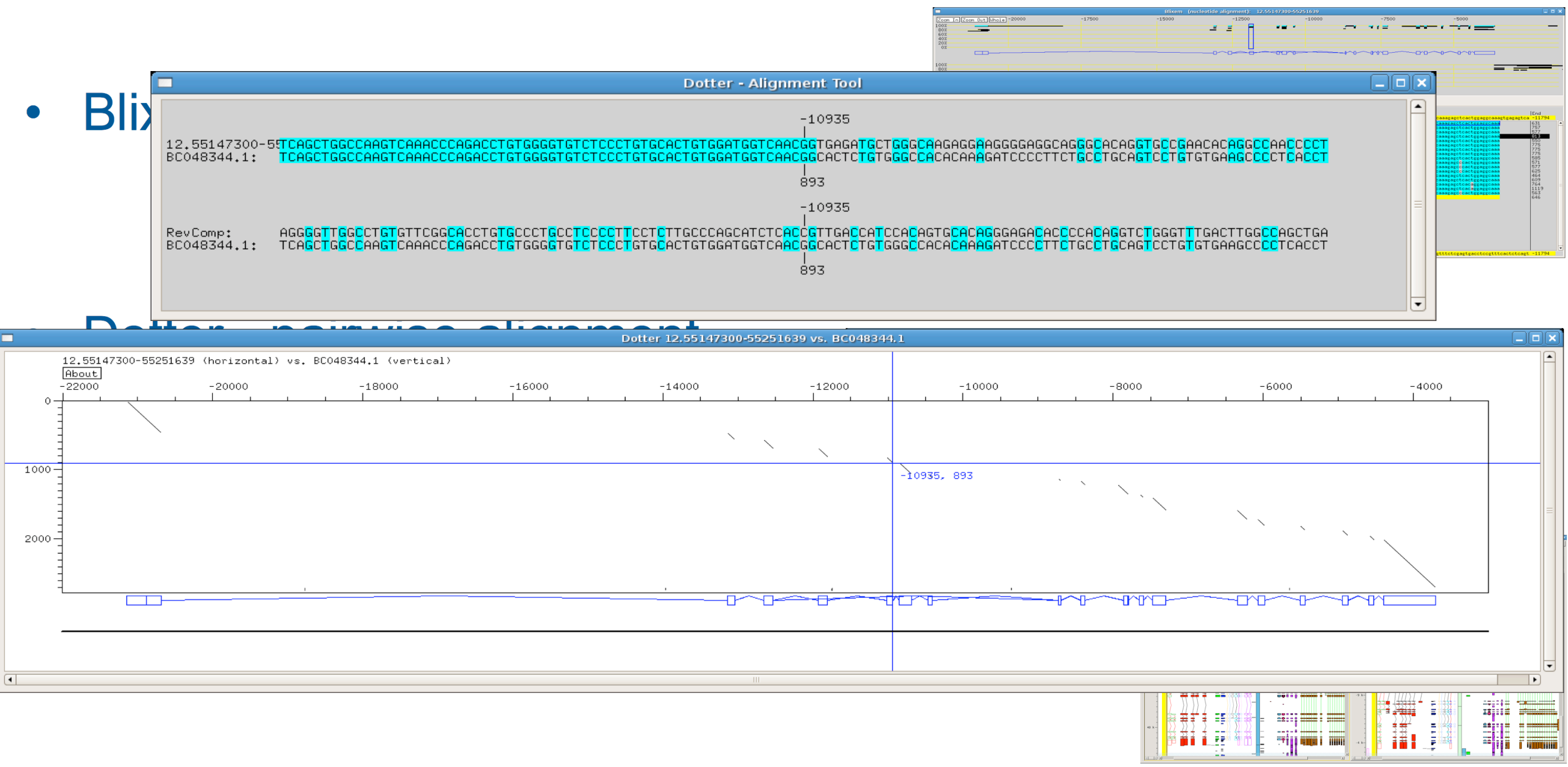




\section{HAVANA - Otterlace and Zmap}

\section{Additional Tools}

- Blixem - multiple alignment

- Dotter - pairwise alignment

- Cross-Species
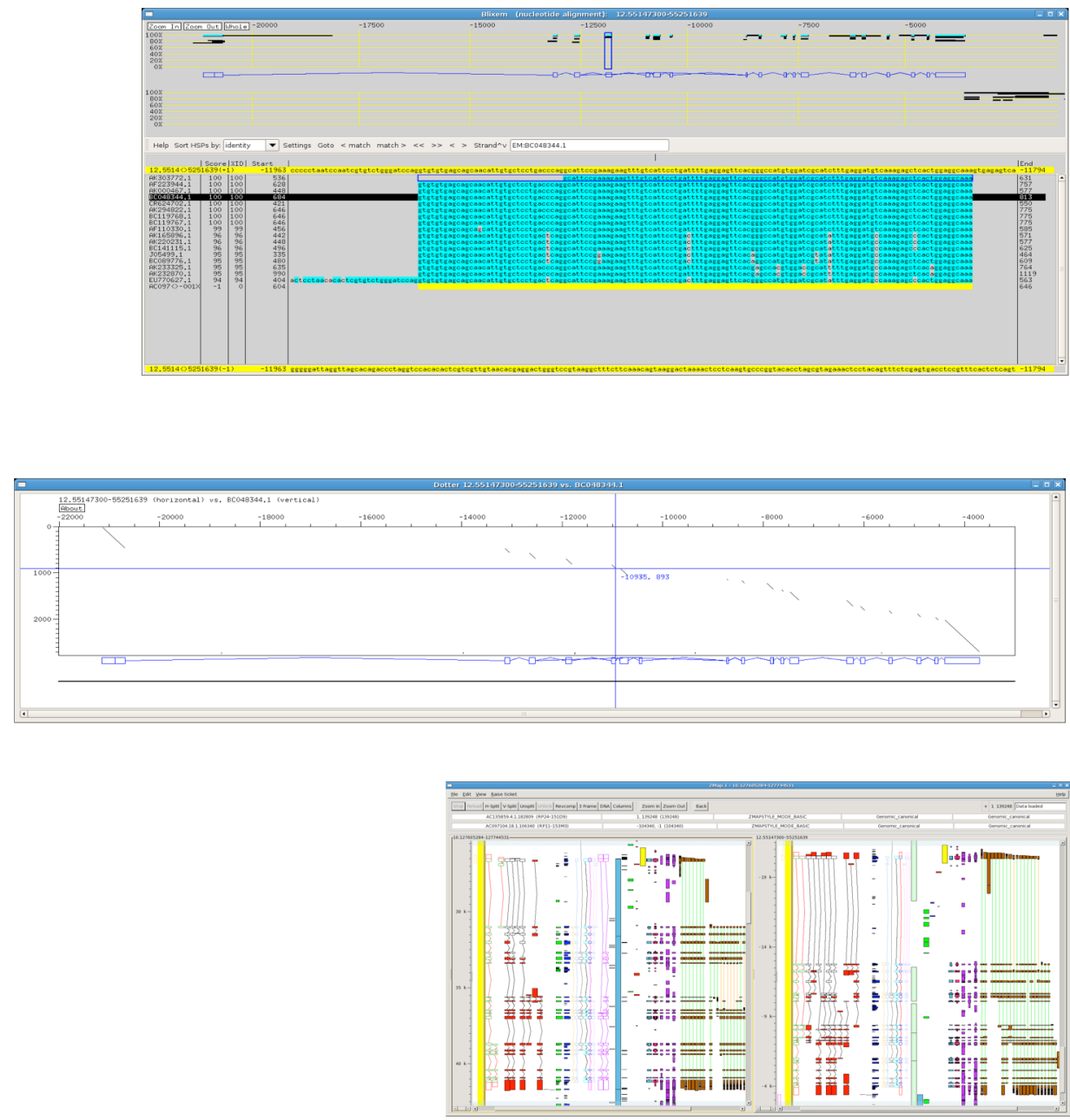

\section{havana}




\section{HAVANA - Otterlace and Zmap}

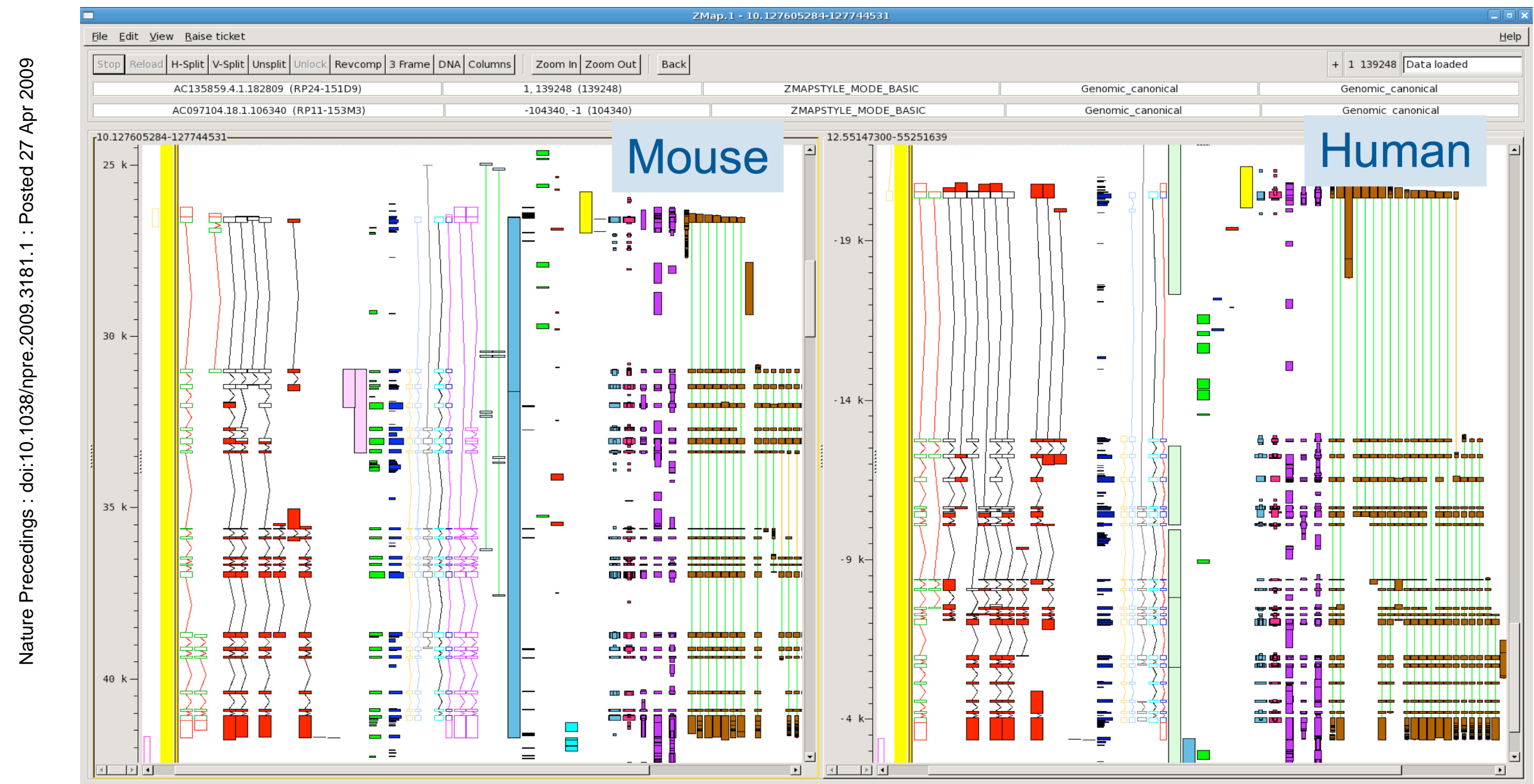




\section{HAVANA - Otterlace and Zmap}

\section{Additional Tools}

- Blixem - multiple alignment

- Dotter - pairwise alignment

- Cross-Species
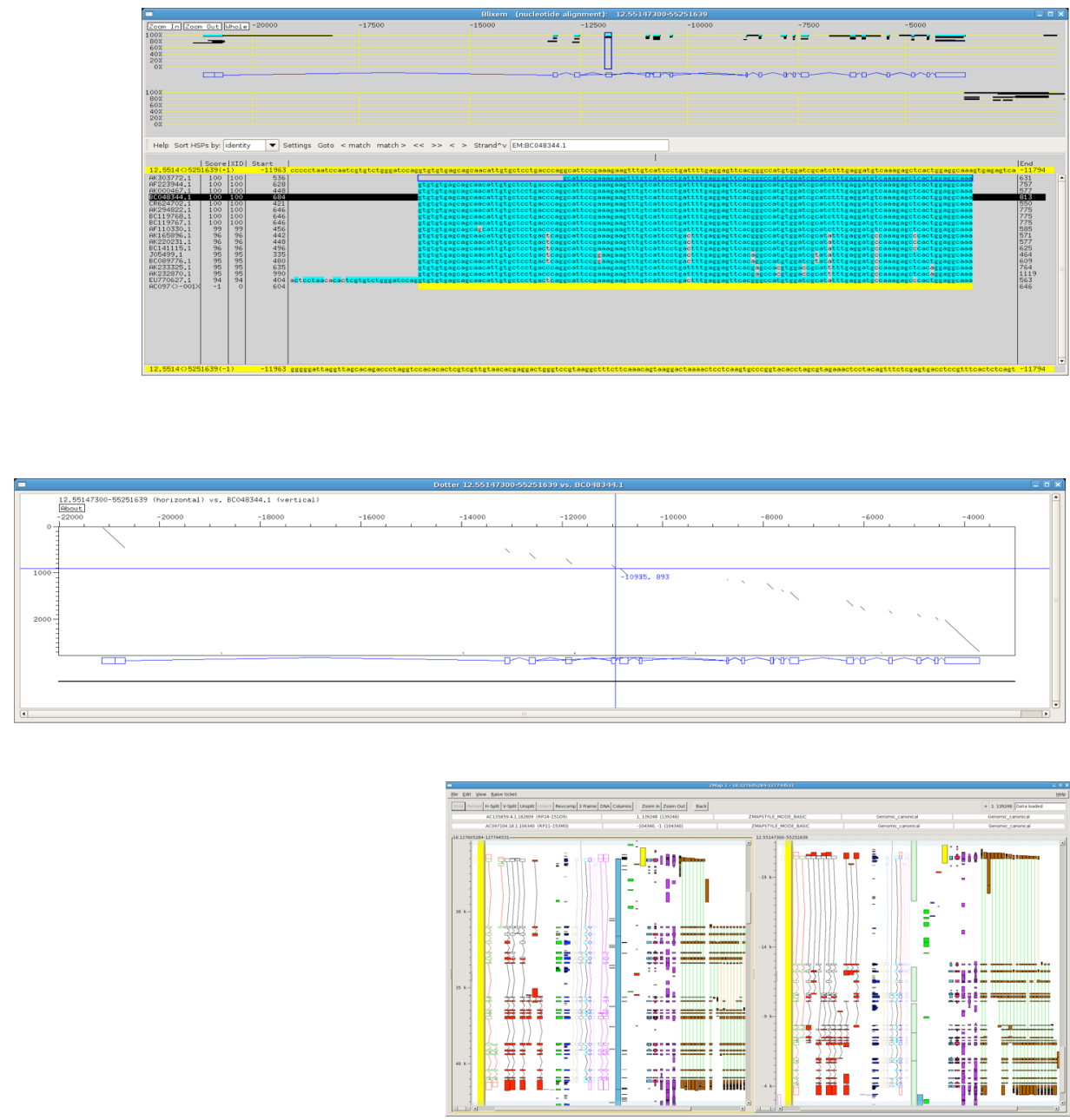

\section{havana}




\section{EUCOMM}

$\sum \begin{array}{cc}\text { Sallcome trust } \\ \text { institute }\end{array} \quad \begin{gathered}\text { 3rd International Biocuration } \\ \text { Conference } 2009\end{gathered}$




\section{EUCOMM (European Conditional Mouse Mutagenesis)}

- Integrated Project funded by the EU Framework 6 programme

- 9 participating members in 4 countries

- UK

- Wellcome Trust Sanger Institute, Hinxton

- MRC, Harwell

- Germany

- Helmholtz Zentrum (formerly GSF), Munich

- CCR-Charité, Berlin

- University of Frankfurt

- University of Technology, Dresden

- France

- Institut Clinique de la Souris, Strasbourg

- Italy

- EMBL, Monterotondo

- NRC, Monterotondo

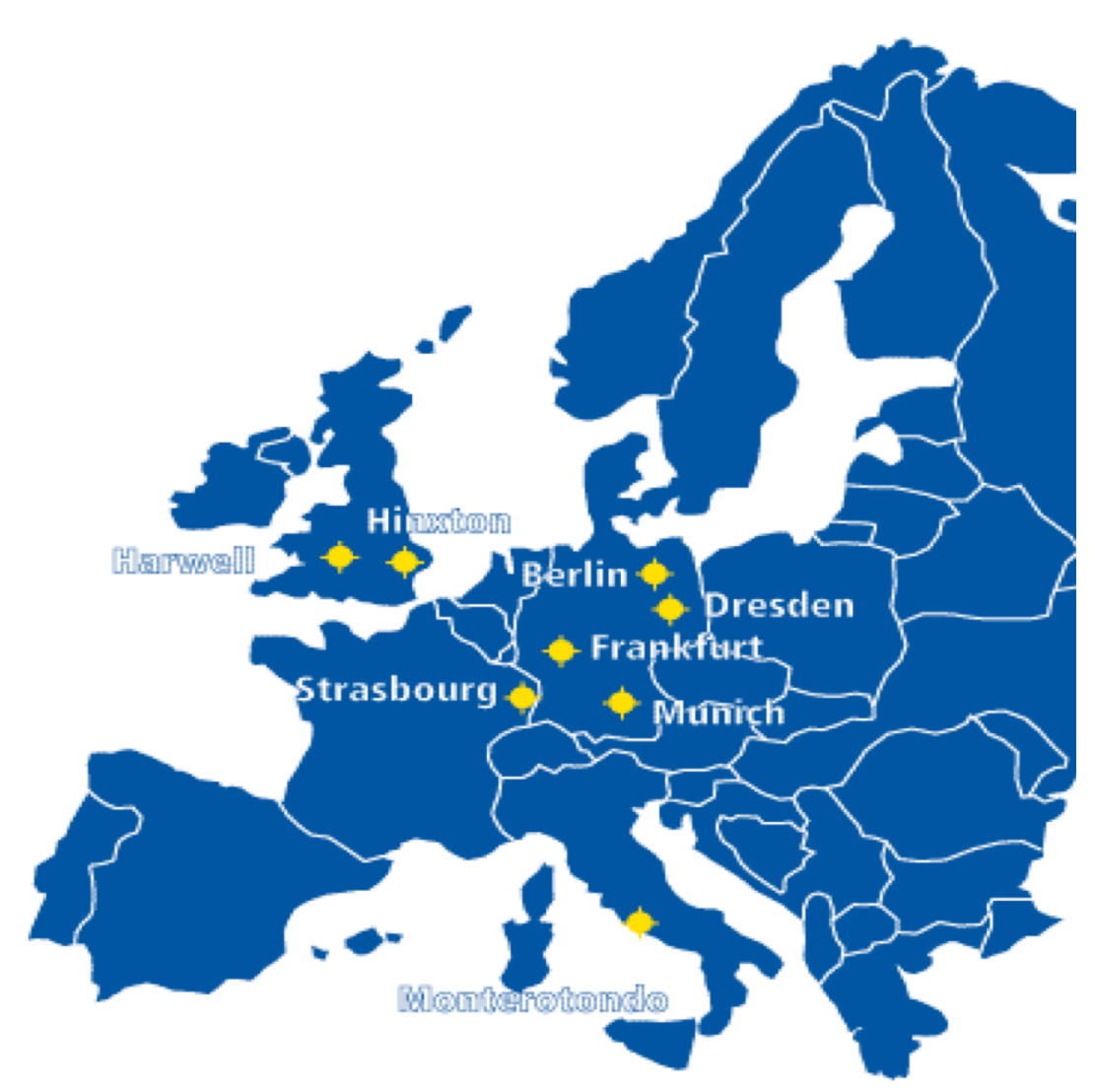




\section{EUCOMM - objectives}

- Generation, archiving and distribution of up to 13,000 conditional mutations in mouse embryonic stem (ES) cells

- 8,000 conditional gene targeting mutations

- 5,000 conditional gene trapping mutations

- Production of up to 320 mouse mutant lines

- Creation of up to 14 mouse lines expressing the Cre recombinase in a tissue-specific manner 


\section{EUCOMM - integration}

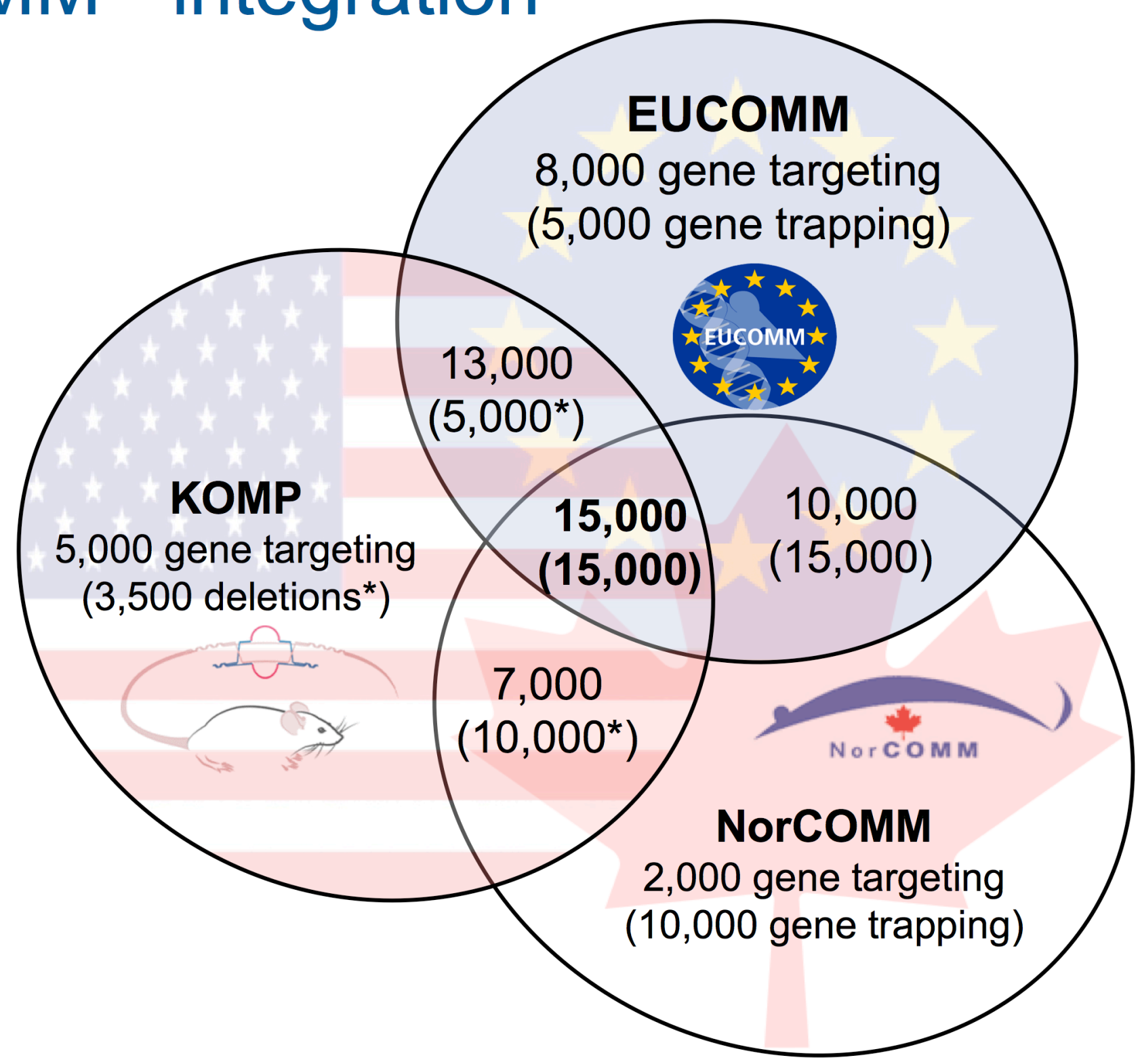

$\sim 3$ years

(extended to 2011) $\sim 5$ years

(2006-2011) 


\section{EUCOMM - vector design}

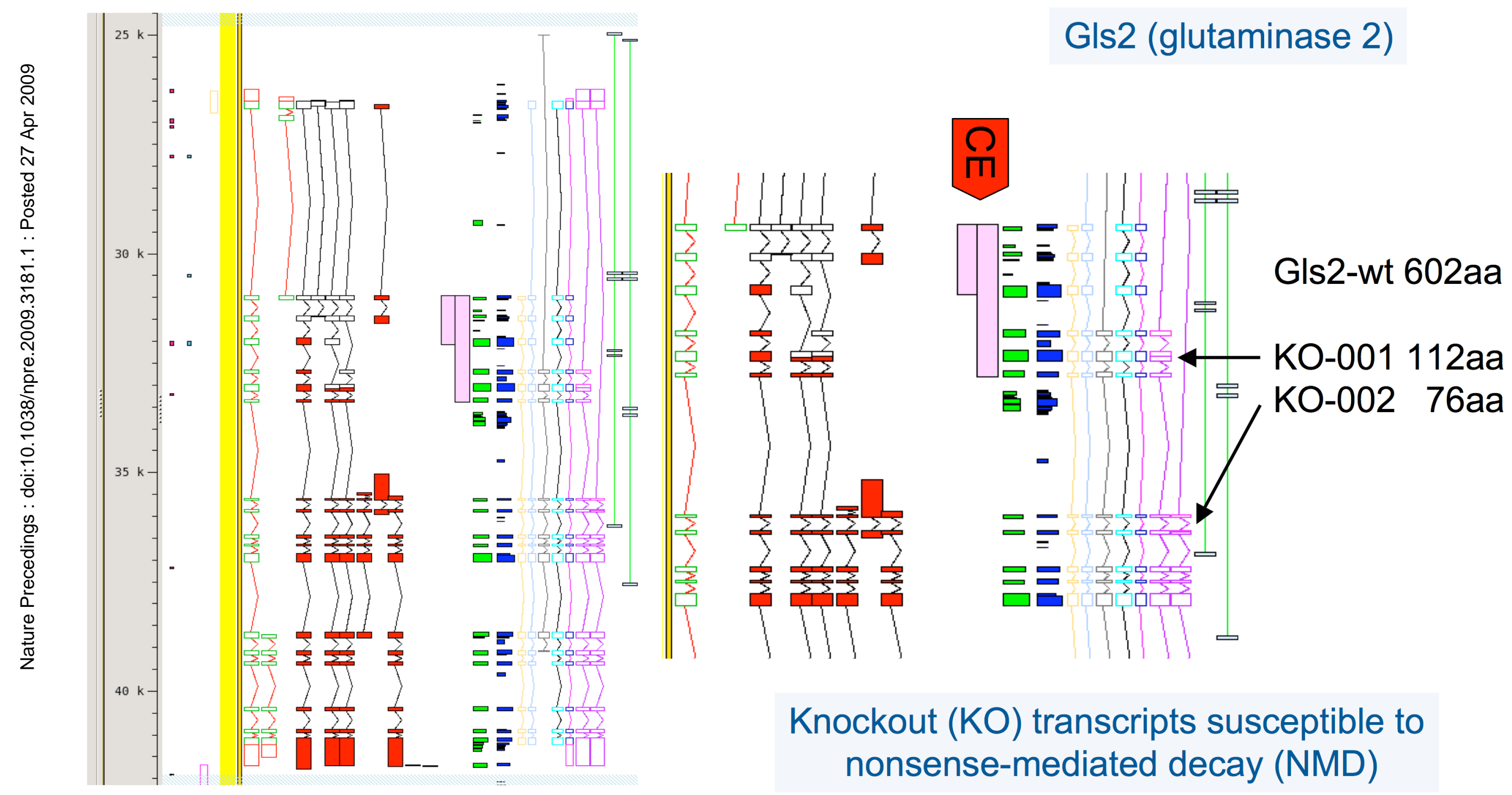




\section{EUCOMM - vector design}
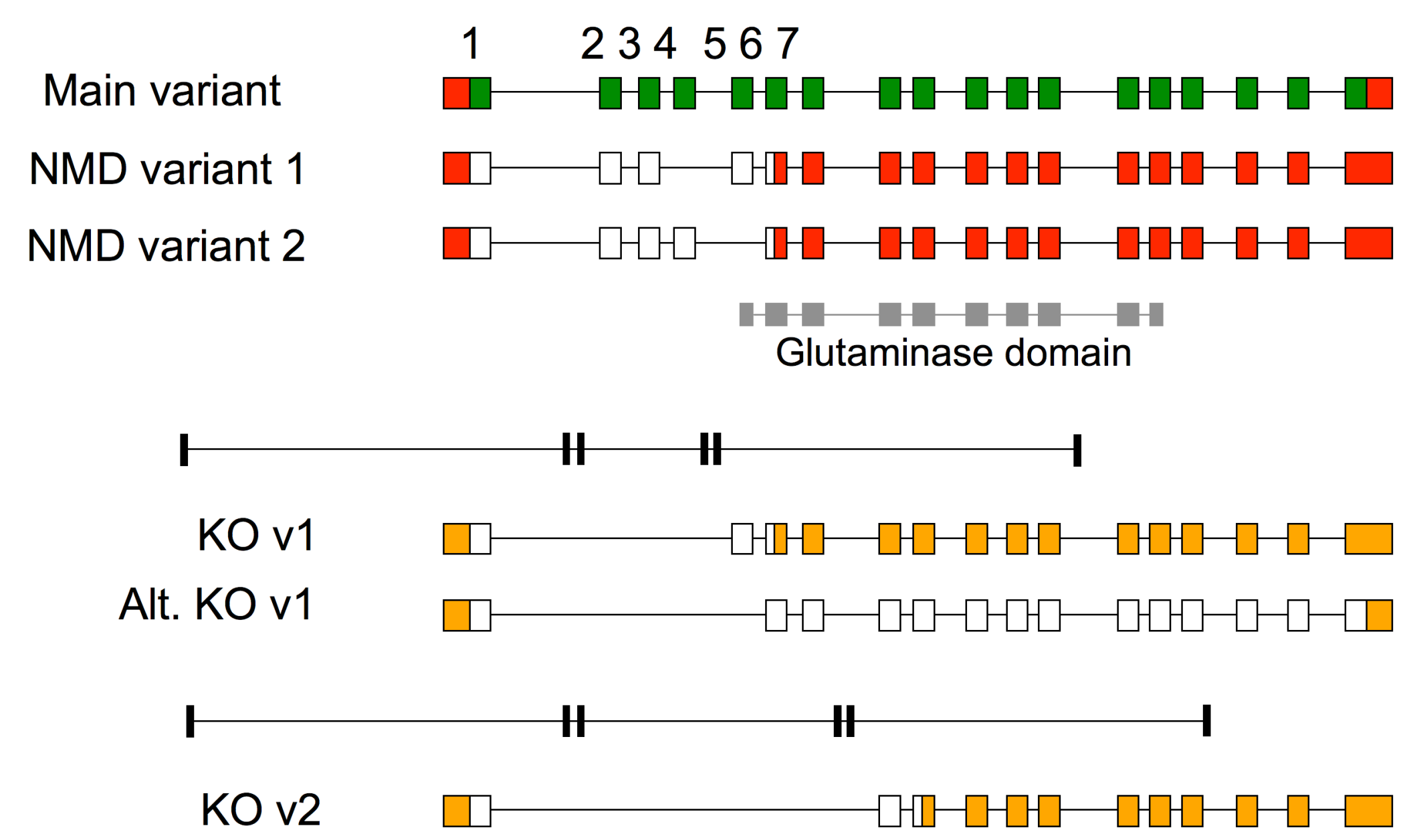


\section{EUCOMM - vector design}

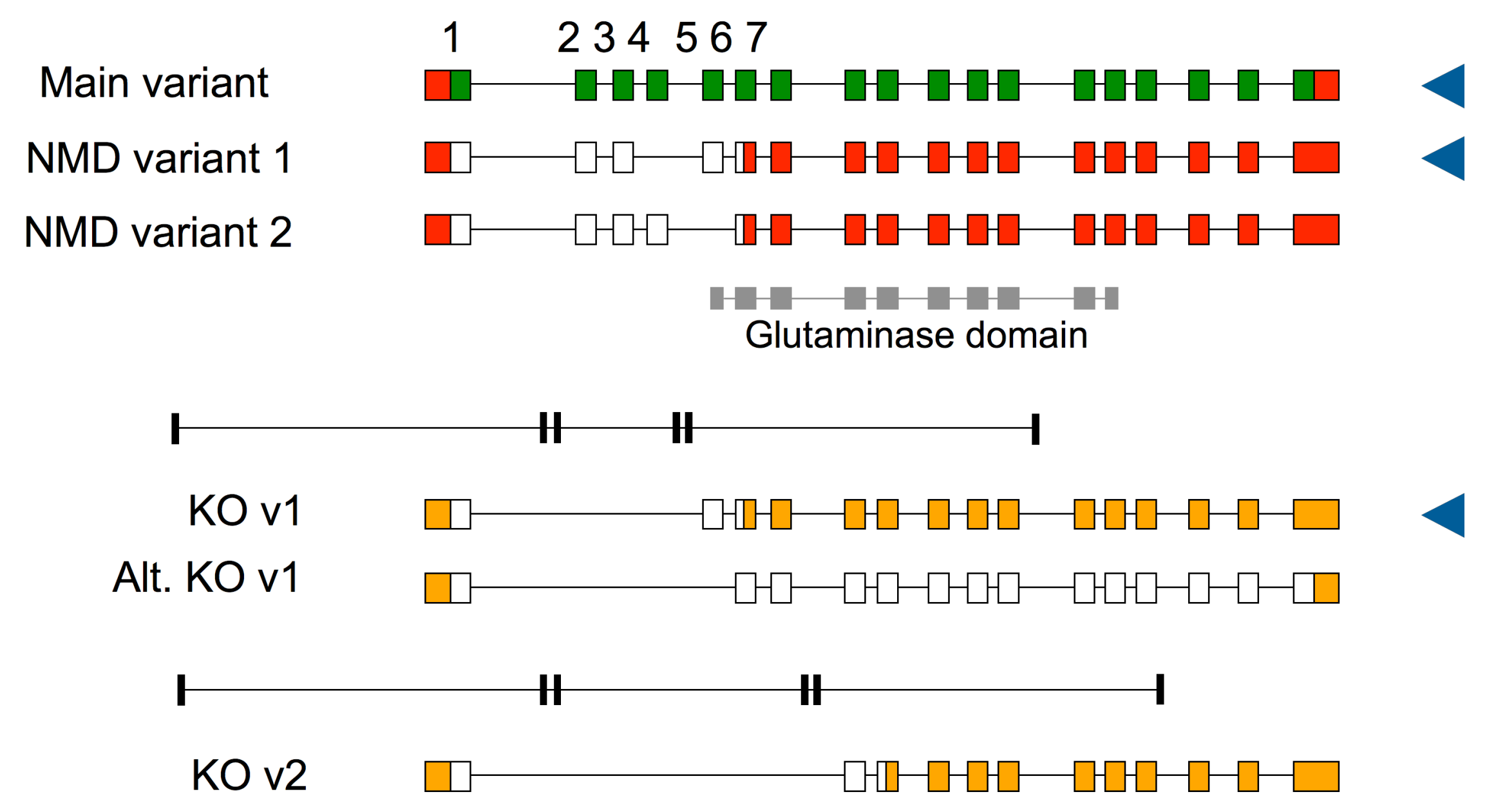




\section{EUCOMM - vector design}
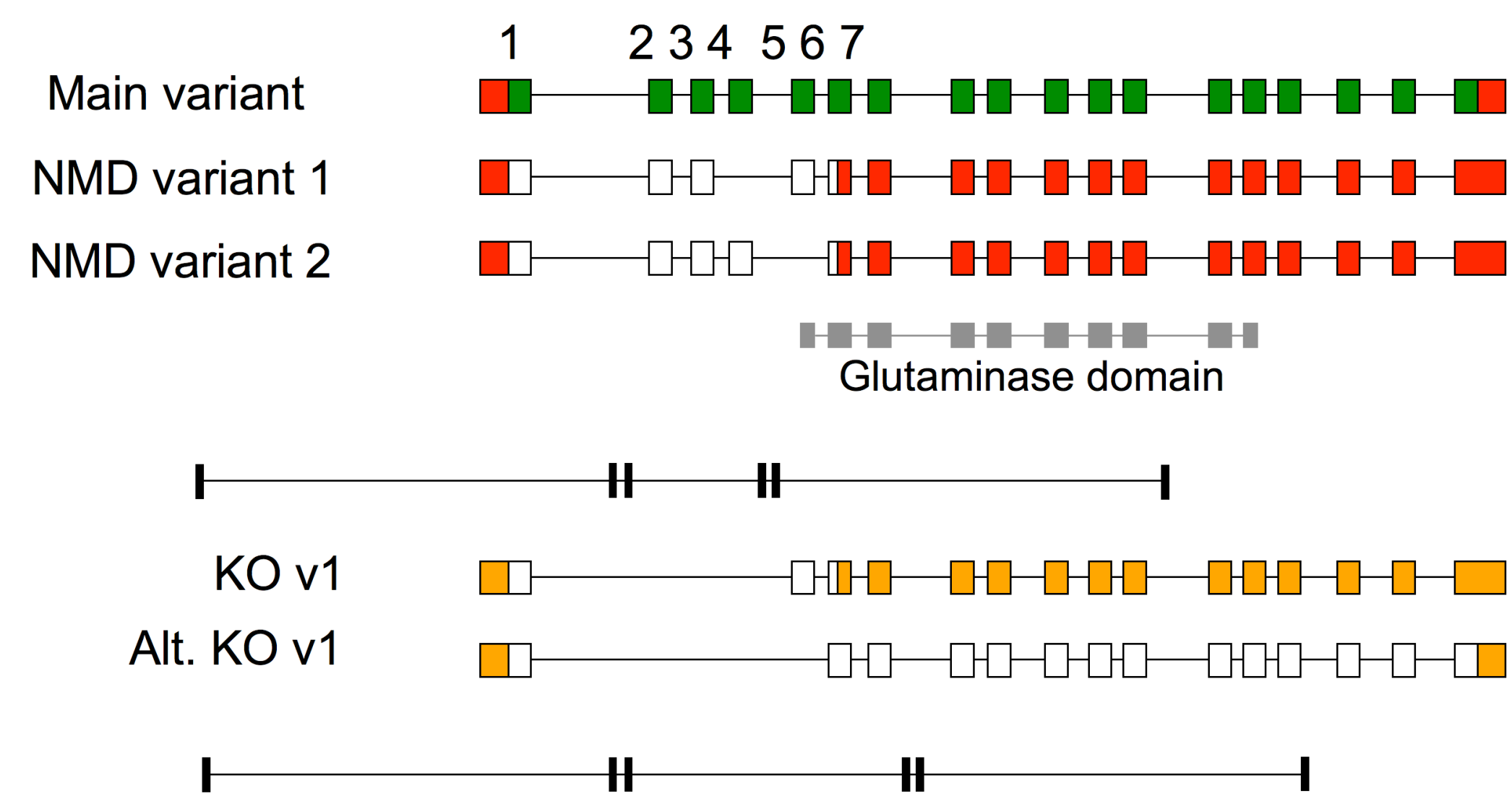

KO v2 $\square \square$ 


\section{EUCOMM - vector design}
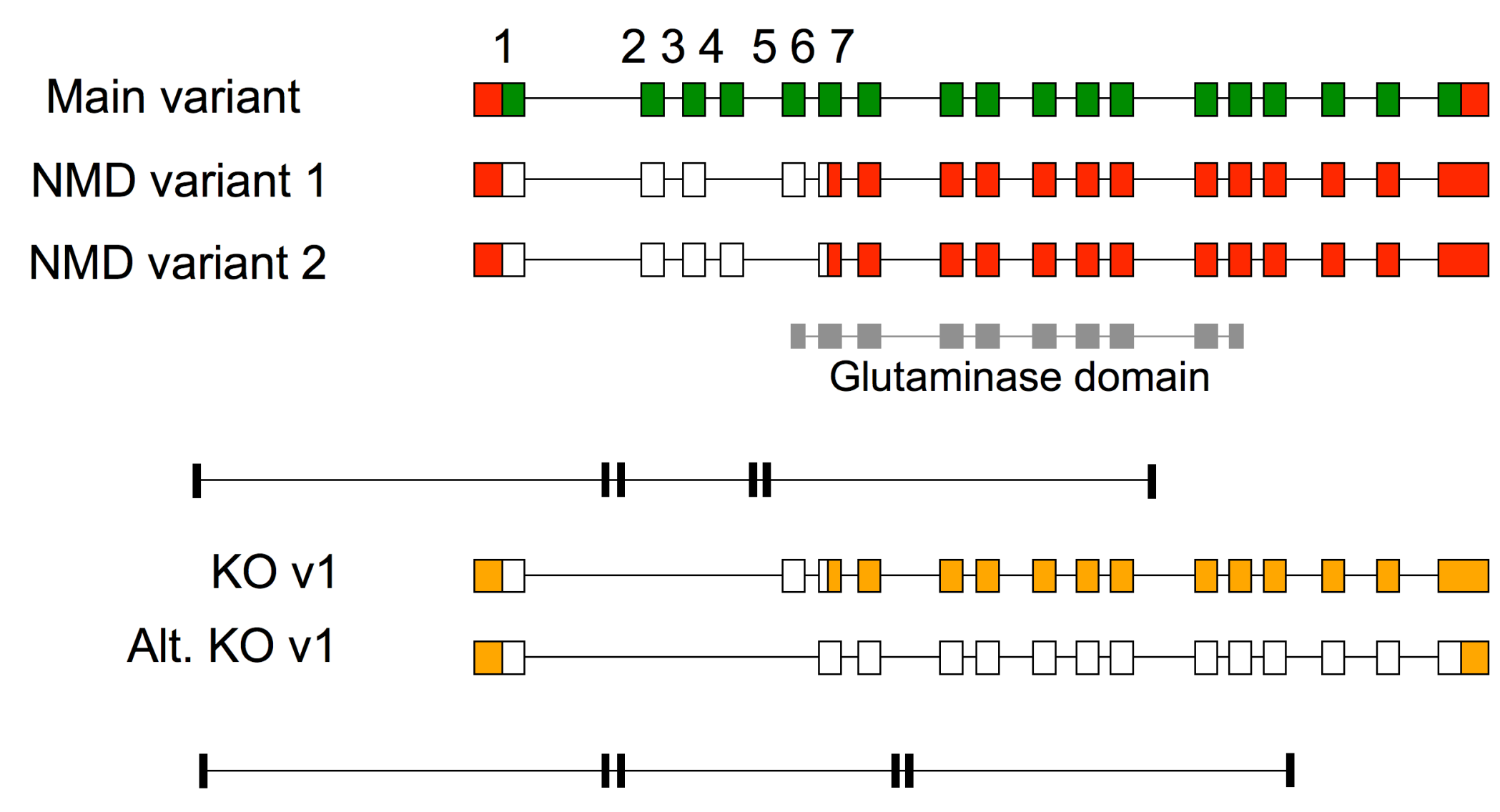

KO v2 


\section{VEGA}




\section{VEGA (Vertebrate Genome Annotation)}

- Based on Ensembl schema

- Contains only manual annotation (eg. HAVANA, WU, MIT, etc)

- Updated releases every 2 months

- Displays knockout (KO) transcripts for EUCOMM/KOMP

http://vega.sanger.ac.uk

\section{Browse a genome}

Homo sapiens [30-03-2009] browse I Ensembl

Mus musculus [30-03-2009]

browse | Ensemb|

Danio rerio [30-03-2009] browse | Ensemb|

Gorilla gorilla [30-03-2009]

browse I Ensembl

Macropus eugenii [30-03-2009] browse

Sus scrofa [16-05-2007] browse I Ensembl

Canis familiaris [14-02-2005] browse I Ensembl 


\section{VEGA}

Vega Mouse ContigView

Search Vega Mouse: Anyything $\quad$ G.

$\begin{array}{lll}\text { Vega vas - Mar } 2009 & \square \text { Chromosome } 10\end{array}$

Your Vega

* Login or Register

Chromosome 10
$12,912,012-13,605,550$

$\square$ Overview

* Vew of Chromosome 10
* Graphical view

* Graphical overview

Export data

* Export from region...

Use Vega to..

* BLAST / SSAHA

$*$ * Export data
$*$ Download data

Information

- Site Map (Mouse)

(1) What's New

O Infornation
O Pcknowledgements

$\exists$ Detailed view

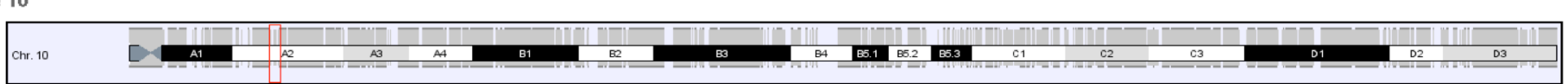

Other links

* Home
$*$ Human

$*$ Human
$*$ Mouse
$*$ Zotrafish

* Zebrafis

* Pig

ef Ensembl Mouse

havana $\$$ sanger
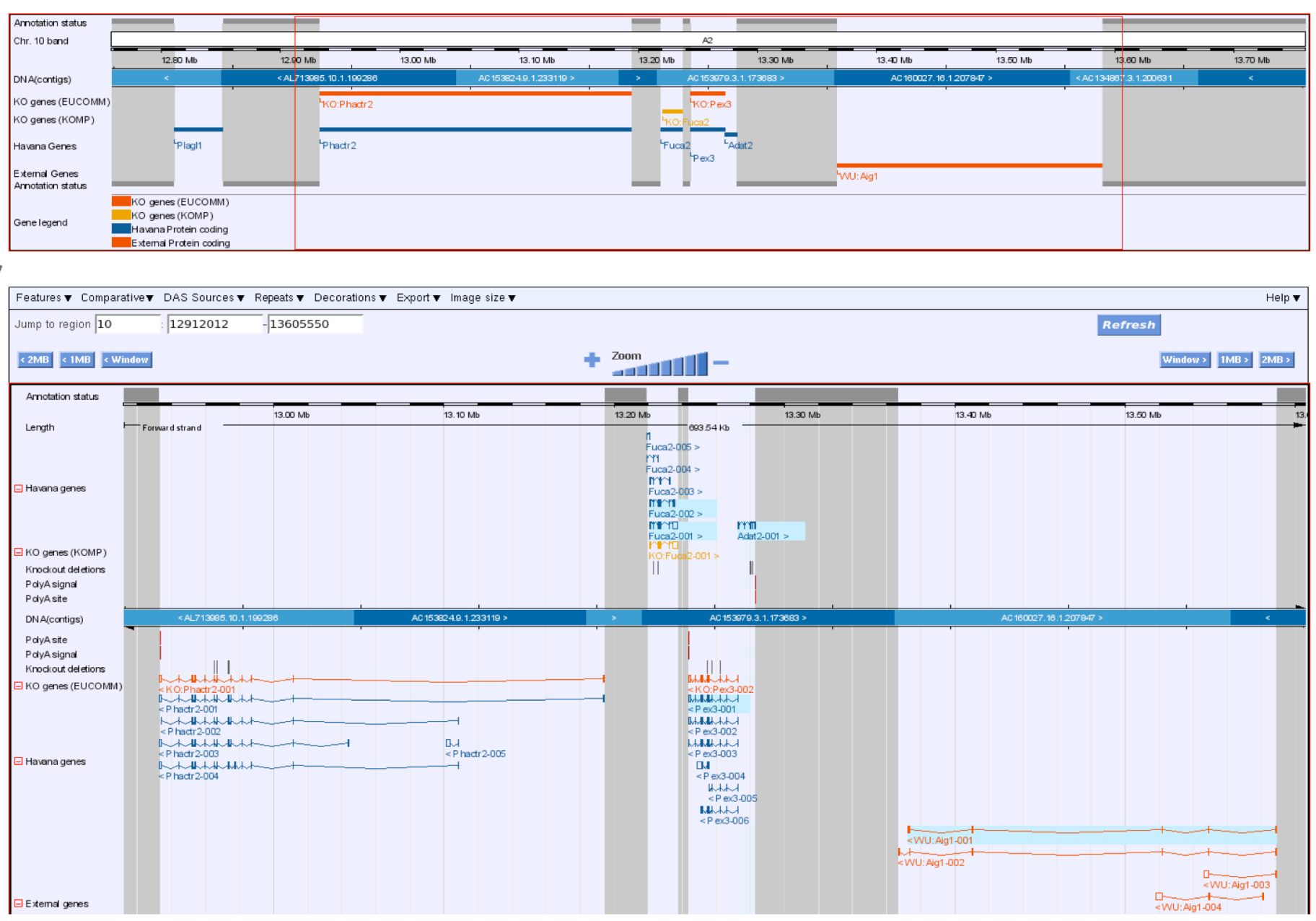


\section{VEGA}

Vega Mouse ContigView $\begin{array}{lll}\text { Voga vas - Mar roo9 } & \\ \text { Your Vega Chromosome } 10 & 0\end{array}$

* Login or Register
O eppout user accounts

Chromosome 10
$12.912,012-13.605 .550$ -

* view of Chromosome 10

* Graphical vlew
$*$ Graphical overview

Export data

* Export from region...

Use Vega to.

* BLAST / SSAHA

* Text search

Information

- Site Map (Mouse)

o what's New

O Information
O Acknowledgements

Other links

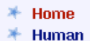

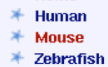

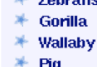

$\underset{\substack{* \\ * \\ * \text { pog }}}{*}$

el Ensembi Mouse

havana IS sanger

$\boxminus$ Detailed view

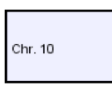
Annotition satuc

DNA(contins) ко genes EUcol ro genes (Kol Hakena Geres

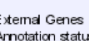
Genel legend

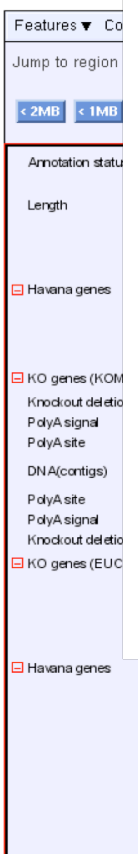

\section{$\square$ KO genes (KOMP)} Knodkout deletions PdyA signa PdyA site

DNA(contigs)

PalyAsite

PdyA signa

Knodkout deletions KO genes (EUCOMM)

(

$\square$ Havana genes

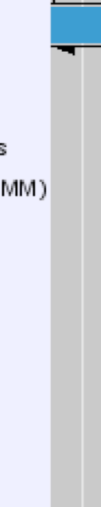

<AL713885. 10.1.198286

$\vdash_{\text {Forward strand }} \quad 13.00 \mathrm{Mb}$

Supporting evidence

Export Peptid

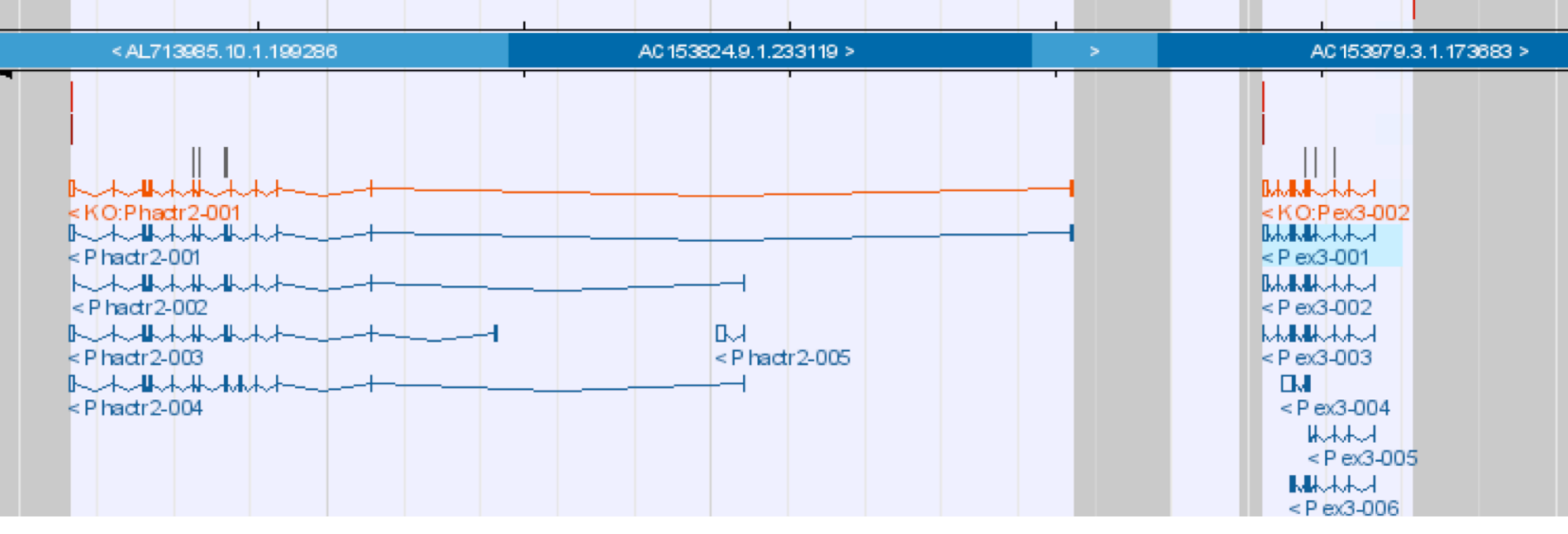

EEtenal gene

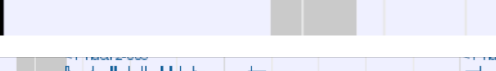

Havana genes

veca_transcript: Pex3-001

Transcript class: Known protein coding Gene type:Known protein coding

Author: Hawana

CCDS:CCD523702.1

Gene:0TMUSG00000020905

Transcr:0TMUST00000049414

Peptide:OTMUSF0000002288

Exon:0TMUSTO0000049414

Export cDNA

ㄴ.t Zoom

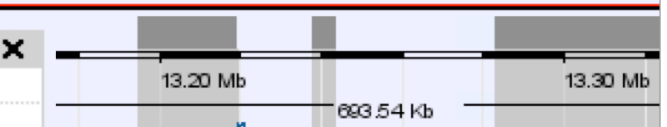

$\mathrm{M} \quad 203.54 \mathrm{~kb}$ Fuca2-005 > $r_{\text {Fuca2-004 }}$ TrYTFuca2-003 IrIn1 IITYY ruca2-001 Aclat2-001 >

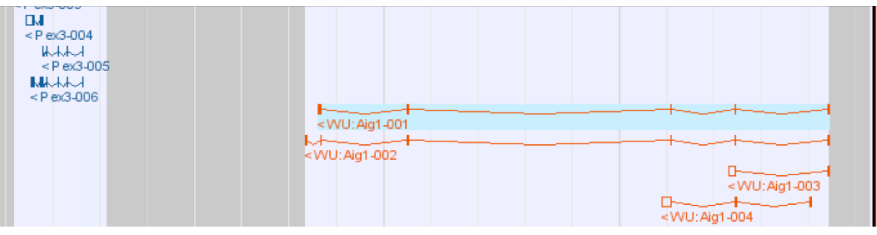

havana rrm 


\section{Results}

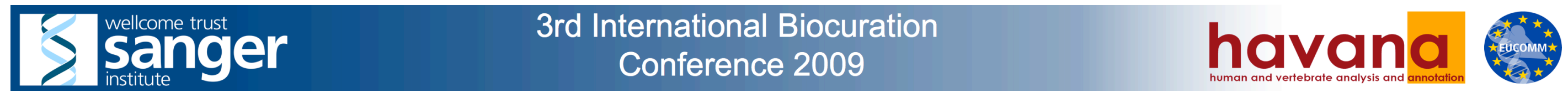




\title{
Results - current status
}

\section{Annotation}

\author{
Annotated protein coding genes $\quad 12,585$ \\ Genes requiring annotation (up to) 4,183 \\ Total $\quad 16,768$ \\ Vectors

$$
\begin{array}{rr}
\text { Awaiting design } & 811 \\
\text { Design completed } & 7,010 \\
\text { Vectors in construction } & 3,927 \\
\text { Complete Targeting Vectors } & 3,004 \\
\text { ES Cells } & 981
\end{array}
$$




\section{Results - High Throughput Gene Targeting}

Database of targeted mouse mutant resources generated by the WTSI for the EUCOMM, KOMP and NORCOMM projects

http://www.sanger.ac.uk/htgt/

http://www.eucomm.org

High Throughput Gene Targeting

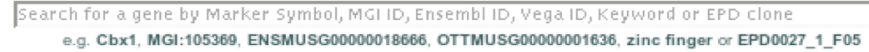

$\Rightarrow$ BioMart (Advanoed Query Interface)

$\Rightarrow$ Browse for Designs

Pipeline Summary

\begin{tabular}{|c|c|c|c|c|}
\hline Stage & EUCOMM & KомР & MGP & Norсомm \\
\hline Mice - Available for distribution & $\underline{0}$ & $\underline{0}$ & $\underline{0}$ & $\underline{0}$ \\
\hline Mice - Genotype confirmed & 148 & $\underline{89}$ & 124 & $\underline{0}$ \\
\hline Mice - Germline transmission & $\underline{67}$ & $\underline{23}$ & $\underline{21}$ & $\underline{0}$ \\
\hline Mice - Microinjection unsuccessful & $\underline{0}$ & $\underline{0}$ & $\underline{0}$ & $\underline{0}$ \\
\hline Mice - Microinjection in progress & $\underline{217}$ & $\underline{55}$ & $\underline{43}$ & $\underline{0}$ \\
\hline ES Cells - Targeting Confirmed & $\frac{981}{(866 \text { shipped) }}$ & $\frac{1042}{(1008 \text { shipped })}$ & $\frac{83}{(223 \text { shipped })}$ & $\frac{0}{(0}$ shipped) \\
\hline ES Cells - Targeting Unsuccessful - Project Terminated & $\underline{2}$ & $\underline{2}$ & 1 & $\underline{0}$ \\
\hline ES Cells - No QC Positives & $\underline{312}$ & $\underline{315}$ & $\underline{48}$ & $\underline{0}$ \\
\hline ES Cells - Electroporation Unsuccessful & $\underline{233}$ & 182 & $\underline{29}$ & $\underline{o}$ \\
\hline ES Cells - Electroporation in Progress & $\underline{210}$ & 405 & $\underline{20}$ & $\underline{o}$ \\
\hline Vector - DNA Not Suitable for Electroporation & $\underline{288}$ & $\underline{375}$ & 15 & $\underline{0}$ \\
\hline vector Complete & $\underline{546}$ & 715 & $\underline{62}$ & $\underline{\mathrm{g}}$ \\
\hline Vector - Initial Attempt Unsuccessful & $\underline{2212}$ & 1751 & 141 & $\underline{0}$ \\
\hline Vector Unsuccessful - Alternate Design in Progress & 105 & $\underline{7}$ & 19 & $\underline{0}$ \\
\hline Vector Unsuccessful - Project Terminated & 4 & $\underline{2}$ & $\underline{3}$ & $\underline{0}$ \\
\hline Vector Construction in Progress & 1610 & 1495 & $\underline{27}$ & $\underline{627}$ \\
\hline Design Completed & $\underline{75}$ & 160 & $\underline{3}$ & $\underline{88}$ \\
\hline Design Not Possible & 7 & $\underline{893}$ & $\underline{27}$ & $\underline{0}$ \\
\hline VEGA Annotation Requested & 765 & 149 & $\underline{0}$ & $\underline{47}$ \\
\hline Alternate Design Requested & $\underline{221}$ & $\underline{5}$ & $\underline{9}$ & 1 \\
\hline Design Requested & $4 \underline{6}$ & 1429 & $\underline{0}$ & 435 \\
\hline Withdrawn From Pipeline & $\underline{324}$ & 428 & $\underline{21}$ & $\underline{29}$ \\
\hline Transferred to NorCOMM & $\underline{216}$ & $\underline{0}$ & $\underline{0}$ & $\underline{0}$ \\
\hline Transferred to KOMP & $\underline{0}$ & $\underline{58}$ & $\underline{0}$ & $\underline{0}$ \\
\hline On Hold & $\underline{3}$ & $\underline{8}$ & $\underline{0}$ & 108 \\
\hline
\end{tabular}




\section{Conclusions}

- Detailed manual annotation is vital for ensuring a high quality conditional knockout

- Benefits include;

- Accurate identification of exon splice variation, including NMD

- Annotation of UTRs

- Analysis of possible reinitiation events in KO transcripts

- Ensures targeting of all coding variants

- Annotation contributed by mouse KO projects available to wider research community 


\section{Acknowledgements}

\section{HAVANA}

Tim Hubbard

Jen Harrow

Catherine Snow

Clara Amid

Denise Carvalho-Silva

Marie-Marthe Suner

- Everyone else

Otterlace and Zmap

James Gilbert

Ed Griffiths

VEGA

Stephen Trevanion
ES Cell Mutagenesis

Bill Skarnes

Manousos Koutsourakis (Vector Construction)

Alejandro Mujica

Vivek lyer (Informatics)

David Jackson

Daniel Klose

ENSEMBL
Funded by

\section{veleometrust}


